\title{
Estimating Traffic Volume to Identify the Level of Service in Major Intersections of Rajshahi, Bangladesh
}

\author{
Abdulla-Al Kafy ${ }^{*}$, Lamia Ferdous ${ }^{1}$, Saleha Akhter Poly ${ }^{2}$, Mahmud Arafat ${ }^{1}$, Sherazum Monira ${ }^{1}$, Md. Shazzu Rahman $^{1}$, \\ Nashid Rahman ${ }^{1}$, Farzana Afroz ${ }^{1}$, Farhana Mahzabin ${ }^{1}$, Tofael Ahmed ${ }^{1}$, Nahid Akhtar Khan ${ }^{1}$, Hossain Mohiuddin ${ }^{3}$ \\ and Nazia Hossain ${ }^{4}$
}

${ }^{1}$ Department of Urban \& Regional Planning, Rajshahi University of Engineering \& Technology (RUET), Rajshahi- 6204, Bangladesh.

${ }^{2}$ Department of Civil Engineering, Rajshahi University of Engineering \& Technology (RUET), Rajshahi- 6204, Bangladesh

${ }^{3}$ Department of Urban \& Regional Planning, Rajshahi University of Engineering \& Technology (RUET), Rajshahi, Bangladesh

${ }^{4}$ Department of Urban \& Regional Planning, Rajshahi University of Engineering \& Technology (RUET), Rajshahi, Bangladesh

Received: 制 June 20, 2018; Published: 眥 August 03, 2018

*Corresponding author: Abdulla-Al Kafy, GIS and Solid Waste Management Specialist, B \& F Company Ltd. Montecristo Building(4-5th Floor), Plot\#NE(K)-10A/2, 176 Gulshan Avenue, Gulshan-2, Dhaka-1212, Bangladesh, India

\section{Abstract}

The increment of vehicles due to the proportional increment of populations and a rapid development of modern society is a major concern in Metropolitan cities in developing countries like Bangladesh. So, it is imperative to monitor traffic volume as well as the quality of transport supply termed as the Level of Service (LOS). The present study is an investigation of the behavior of mixed traffic flow in Rajshahi city of Bangladesh. Field Traffic volume survey was carried out to determine the level of service at 3 major Unsignalized intersections in Rajshahi city corporation (RCC). Level of service (LOS) was determined by volume capacity ratio and peak hour factor (PHF) method. Nature of traffic flow in Rajshahi city is heterogeneous. So, this heterogeneous or mixed traffic are simplified by Passenger car unit (PCU). Then estimated PCU was used to determine LOS. LOS was calculated for both directions of roads. Auto rickshaw, easy bike and Rickshaw are the dominant vehicles in Monicottor, Vodra, and Laxmipur intersection. According to PHF method and V/C ratio method, LOS of Monicottor intersection is very unstable and worst. At Vodra intersection which consists of three legs, Talaimari to Vodra lane contains highest traffic volume at evening peak and the LOS of Vodra to Padma Residentail area is very worst in nature after analyzing both V/C ratio and PHF method. Considering and evaluating all the findings it can be recommended that Restriction for truck movement in daytime should be applied in Monicottor intersection and width of Monicottor to Sondighir mor and Vodra to Padma residential area road need to be increased to make the traffic flow suitable. Also, incorporation of an effective traffic signal, traffic rules and regulation should be applied and maintained properly in the worst condition intersection to accelerate the traffic flow in RCC area.

Keywords: Passenger Car Unit; Level of service; Traffic Volume; peak hour factor; Intersection; Rajshahi

Abbreviations: LOS: Level of Service; RCC: Rajshahi city corporation; PHF: peak hour factor; PCU: Passenger car unit

\section{Introduction}

For the economic development, good transportation system is very important [1-3]. In transportation engineering traffic volume study is a baseline. Engineering operations and management are successfully completed by using it [4]. Traffic Volume survey plays a significant role to determine the existing condition and to forecast the future condition of traffic volume [5]. The road traffic in developing countries like Bangladesh are highly heterogeneous comprising of the traffic of different static and dynamic characteristics [6,7]. Again, Traffic volume data is very important as it is used to estimate capacity of a road and level of service of that given road under the combination of traffic at any hour of a day $[8,9]$. LOS of a traffic facility defines as a concept used to determine the performance and quality of traffic service to a given flow rate [10]. Levels of service are defined as six categories from A to F and category. A represents best operating condition on the other hand $\mathrm{F}$ represents the worst [11]. 
In Rajshahi city, the increment of traffic volume and congestions are two quickly developing problems. Nowadays, it is common to see traffic congestions at intersections at peak hours in the morning and evening. According to a report, traffic volume is increasing in last few decades and was 19397 in 2015 with annual growth rate $6.1 \%$ in this city [12]. This may be due to Poor road planning and sub-standard geometric conditions of selected intersections [13]. Intersections become very congested if traffic volume are high, make inefficiency as a result peoples suffer delay and frustration [14]. A rapid escalation in the number of motor vehicles, greater availability of used vehicles, the relative reduction in prices result traffic congestions [15]. Due to traffic congestion, air pollution, fuel usage, and travel time [16,17]. Therefore, it is a significant issue to investigate traffic volume and to monitor the quality of transport supply in terms of level of service for major intersections of Rajshahi city corporation (RCC). Traffic volume count of this study will be helpful for planning, accident analysis [18], design and operation, for roadway of Rajshahi city [19] as well as future traffic demand forecasting.

To estimate traffic volume at selected intersections, a case study was made at 4 major intersections during morning (8am$10 \mathrm{am})$, noon (12pm-2pm) and evening (4pm-6pm). To analyze mixed or heterogeneous traffic, a simplification is developed by (add authors name) to convert the different types of vehicles into equivalent number of passenger cars named Passenger car unit or PCU [6]. Finally estimated PCU value are used to determine LOS on three or four legs divided intersections. Level of service (LOS) was determined by volume capacity ratio and peak hour factor method.

\section{Literature Review}

LOS is very effective approach to identify the existing traffic condition of any intersection. Numerous studies have been conducted by different researchers in which they describe the procedure about how to calculate the LOS using various methods.

\section{Related Works in Foreign Countries}

A concept was first developed in 1965 for highway named highway capacity manual (HCM) to define level of service and classify it by a range from $\mathrm{A}$ to $\mathrm{F}$ for highway [20]. It is very important to analyze the traffic performance for design, maintenance, rehabilitation, and planning of roads. Performance evaluation of traffic in a highway is expressed by a term Level of service. It is a method which can explain traffic conditions for an existing or proposed transportation facility operating based upon current or projected traffic demand [21]. Capacity and level of service are analyzed to get the delay of the analyzed facilities. This Analysis is two types. One is empirical, another is analytical. The empirical model is established on the basis of regression analysis on the other hand the analytical model is based on the gap-acceptance theory [22]. An attempt is made by Ankit N Mahidadiya and Prof. Jayesh Juremalani to estimate passenger Car unit (PCU) in an urban intersection [23]. A study was made in malaysia by jamil et al. using aaSIDRA (full abbreviate of aaSIDRA) intersection version 5.1 software to analyze capacity, level of service at unsignalized intersection. Main purpose was to analyze factors affecting level of service at a junction [24]. Rao et al. followed HCM (highway capacity manual) 2000 to evaluate the capacity, control delay and Level of service of vehicular streams and traffic parameters were abstracted by the videography for 3 uncontrolled intersections in India [25]. Mithun Mohan and Satish Chandra proposed three methods for the estimation of PCU at UI under highly heterogeneous traffic conditions. First one is PCU based on occupancy time, second one is PCU based on potential capacity, and last one is PCU based on queue clearance rate [26].

\section{Related Works in Bangladesh}

Several research programs have been developed in foreign countries, but very limited studies have been made in this selected topic in Bangladesh. A case study like physical feature s survey, delay time survey, parking survey, traffic volume survey was done to find out the condition of traffic and transportation at Central Business Area of Rangpur city [27]. A study was developed by chisty, islam and mishuk to identify the existing level of service of agrabad to CEPZ Road in Chittagong city. To calculate LOS, a traffic survey was carried out to determine traffic volume, capacity, and speed of that existing road [28].

\section{Related Works in Study Area}

During the literature review, there are no studies were found about estimation of traffic volume at intersections to calculate level of service at intersections in Rajshahi city.

\section{Materials and Methods}

\section{Description of Study Area}

Rajshahi is a metropolitan city in Bangladesh and a major urban, commercial and educational Centre of North Bengal [29]. The study is carried out in Rajshahi City Corporation, located in Northwest part of Bangladesh. There are 4 thanas (Administrative Unit) in Rajshahi City Corporation which include 30 wards Figure 1 . There are 10 city corporations in Bangladesh and Rajshahi is one of the oldest city corporations, which is established in 1991[29]. In the previous decade Rajshahi is called a city of rickshaw but now it is called a city of both rickshaw and auto-rickshaw and easy bike [2]. In Rajshahi city, 63\% commercial vehicles transport passenger and carry freight [12]. The nature of all intersections is Non-signalized. Most busy intersections were selected named Vodra, Laxmipur, Monicottor.

\section{Road Geometry of Intersections}

Three roads intersected at Vodra intersection are TalaimariVodra, Railway Station-Vodra \& Padma Residential area- Vodra. A sculpture is situated named "Smriti Amlan" in the center of intersection which radius is 40 feet. The Talaimari-Vodra road has four lanes. The "Railway station-Vodra" road has four lanes with two sided footpath. The Padma residential-Vodra road has two lanes with two-sided footpath Figure 1. Laxmipur intersection consists of four roads named Bazar to Laxmipur, Railgate to Laxmipur, C\&B to Laxmipur \& court station road to Laxmipur. In the Centre of 
intersection, a sculpture is situated named Mintu mia chottor and its radious is of the center is $29 \mathrm{ft}$. Court station road is two lanes and other road is four lanes Figure 2.

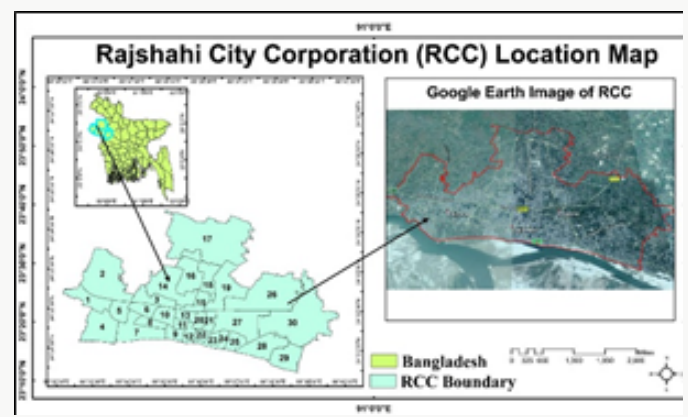

Figure 1: Location Map of Study area.

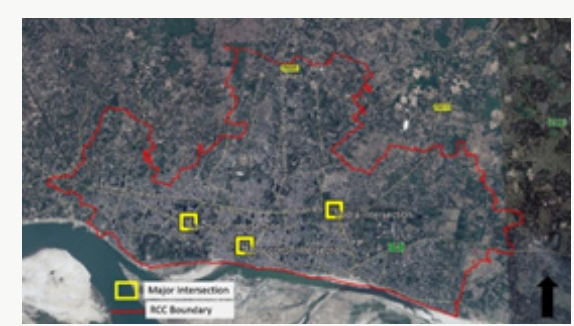

Figure 2: Location of Three Major Intersection in RCC area.

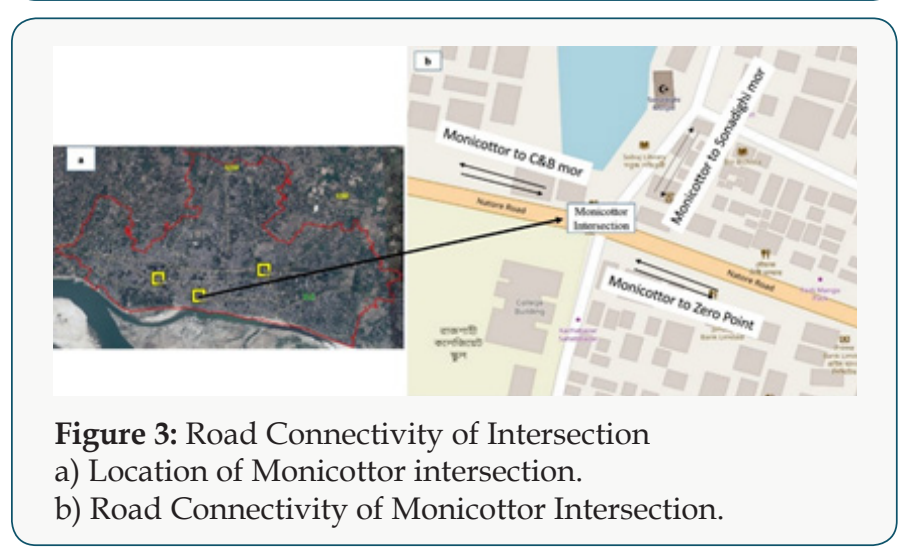

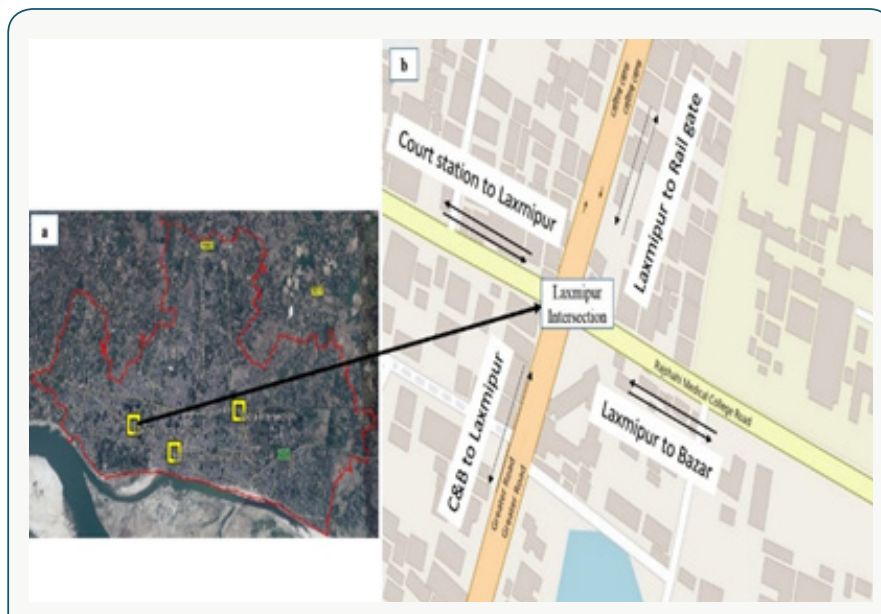

Figure 4: Road Connectivity of Intersection

a) Location of Laxmipur intersection.

b) Road Connectivity of Laxmipur Intersection.

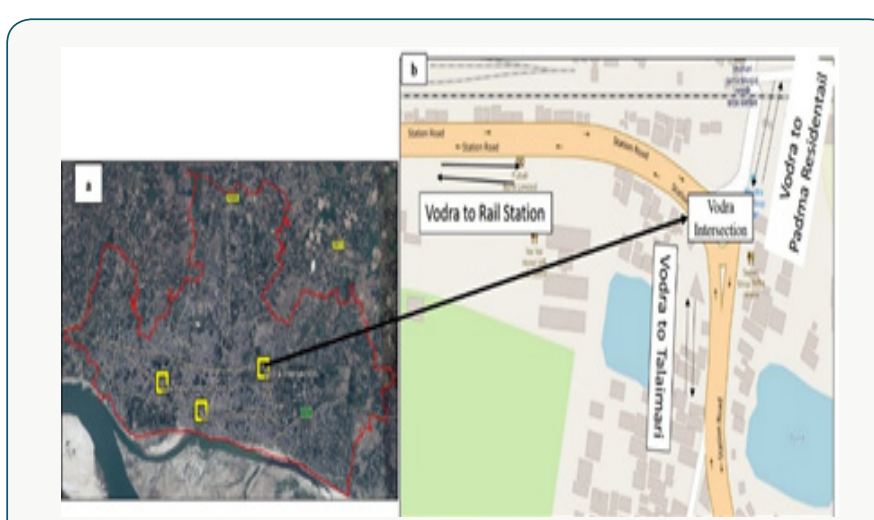

Figure 5: Road Connectivity of Intersection

a) Location of Vodra intersection.

b) Road Connectivity of Vodra Intersection.

The busiest intersection is Monicottor which consists of 3 roads. In east, west and north direction are Zero point, CNB area, Sonadighi mor. Vehicles type are Auto rickshaw, Rickshaw, CNG, Microbus, Truck, Cycle, Motor cycle, bus (Figures 3-5) (Tables 1 \& 2).

Table 1: Road Geometry of Three major intersection in RCC area.

\begin{tabular}{|c|c|c|c|c|c|c|}
\hline \multirow{2}{*}{$\begin{array}{l}\text { Intersection } \\
\text { Name }\end{array}$} & \multirow{2}{*}{ Road Name } & \multicolumn{2}{|c|}{ Lane Width (ft.) } & \multirow{2}{*}{ Median (ft.) } & \multicolumn{2}{|c|}{ Footpath width (ft.) } \\
\hline & & Right & Left & & Right & Left \\
\hline \multirow{3}{*}{ Vodra } & Vodra to Talaimari & 24 & 24 & 6 & 10 & 10 \\
\hline & Vodra to Rail Station & 24 & 24 & 6 & \multicolumn{2}{|c|}{ No footpath } \\
\hline & Vodra to Padma R/A & & & No Median & 10 & 10 \\
\hline \multirow{4}{*}{ Laxmipur } & Laxmipur to Court Station & \multicolumn{2}{|c|}{40} & No Median & 10 & 10 \\
\hline & Laxmipur to Railgate & 20 & 20 & 7 & 10 & 10 \\
\hline & Laxmipur to Bazar & 20 & 20 & 7 & 10 & 10 \\
\hline & Laxmipur to C \& B mor & 20 & 20 & 7 & 10 & 10 \\
\hline \multirow{3}{*}{ Moni Cottor } & Moni Cottor to C \& B mor & 40 & No Median & 10 & 10 & \\
\hline & Moni Cottor to Saheb Bazar & 20 & 20 & 5 & 10 & 8 \\
\hline & Moni Cottor to Sonadighir mor & 20 & \multicolumn{2}{|c|}{ No Median } & \multicolumn{2}{|c|}{ No footpath } \\
\hline
\end{tabular}


Table 2: Traffic performance measurement by V/C ratio (HCM 2010) (Mathew \& Bombay, 2017; Wikipedia, 2017).

\begin{tabular}{|c|c|c|}
\hline LOS & V/C Ratio & Detailed Description \\
\hline A & $0.00-0.35$ & $\begin{array}{l}\text { Represents the best operating conditions and is considered free flow. Individual users are virtually unaffected by } \\
\text { the presence of others in the traffic stream. }\end{array}$ \\
\hline B & $0.35-0.58$ & Represents reasonably free-flowing conditions but with some influence by others. \\
\hline $\mathrm{C}$ & $0.58-0.75$ & $\begin{array}{l}\text { Represents a constrained constant flow below speed limits, with additional attention required by the drivers to } \\
\text { maintain safe operations. Comfort and convenience levels of the driver decline noticeably. }\end{array}$ \\
\hline $\mathrm{D}$ & $0.75-0.90$ & $\begin{array}{l}\text { Represents traffic operations approaching unstable flow with high passing demand and passing capacity near } \\
\text { zero, characterized by drivers being severely restricted in maneuverability. }\end{array}$ \\
\hline $\mathrm{E}$ & $0.90-1.00$ & $\begin{array}{l}\text { Represents unstable flow near capacity. LOS E often changes to LOS F very quickly because of disturbances (road } \\
\text { conditions, accidents, etc.) in traffic flow. }\end{array}$ \\
\hline $\mathrm{F}$ & $>1.00$ & $\begin{array}{l}\text { Represents the worst conditions with heavily congested flow and traffic demand exceeding capacity, characterized } \\
\text { by stop-and-go waves, poor travel time, low comfort and convenience, and increased accident exposure. }\end{array}$ \\
\hline
\end{tabular}

\section{Methodology}

The main objective of this research is to identify the LOS of different intersections. LOS is related with Modal composition of various transport, Road capacity and Road geometry. Modal composition describes the key operational, commercial advantages and properties of any transport in terms of cost, speed, accessibility, frequency, safety, comfort, etc. In this research to achieve the LOS, traffic volume survey was carried out to count mixed vehicles, geometric feature survey. All traffic data were collected into three phases like morning peak (8-10am), afternoon off peak (12-2pm) and evening peak (4-6pm) and each peak was continued for 2 hours duration (Transport, 2004). Geometric feature survey is needed to identify the existing road capacity. To identify the existing supply and capacity conditions of various intersections road length, width of carriageway, footpath, median, shoulder, number of legs and control system etc. data has been collected by conducting field survey. The calculation of Passenger car unit or PCU is very important to analyze the mixed or heterogeneous traffic and PCU is a simplification which convert the different types of vehicles into equivalent number of passenger cars [26]. By conducting a private survey in 2014, 11,000 battery operated auto-rickshaws, 35,000 rickshaws, 800 CNG-rickshaws and auto-tempos, 1,500 human hauler, 1,200 rickshaw vans and 1,500 cars and micro-buses are investigated [3] (Table 3).

Table 3: LOS with respect to its PHF.

\begin{tabular}{|c|c|}
\hline Peak Hour Factor Value & LOS \\
\hline 0.7 or less & A \\
\hline 0.8 or less & B \\
\hline 0.85 or less & C \\
\hline 0.90 or less & D \\
\hline 0.95 or less & E \\
\hline$>1$ or less & F \\
\hline
\end{tabular}

To estimate the LOS two useful methods have been applied. The volume-capacity ratio is 1 st of them. Volume capacity ratio (V/C) is one of the most used index to assess traffic status in cities, in which
$\mathrm{V}$ is the total number of vehicles passing a point in one hour and $\mathrm{C}$ for the maximum number of vehicles that can pass a certain point at the reasonable traffic condition, "Volume -Capacity Ratio (V/C) is a measure that reflects mobility and quality of travel of a facility or a section of a facility. It compares roadway demand (vehicle volumes) with roadway supply (carrying capacity) [18]. The V/C method is associated with LOS and determining how well a roadway is performing. This measure can alert transportation providers to areas where traffic mitigation measures should be considered. V/C ratio was calculated by following formula [30,31].

$$
\begin{aligned}
& \text { Volume canacitv ratio }=\frac{\text { Total hourlv PCU }}{\text { Capacity }} \\
& \text { Capacity, C }=\frac{\text { Highest design capacity* effective width }}{12}
\end{aligned}
$$

The 2nd method to calculate the LOS is Peak Hour factor (PHF) method. Traffic engineers focus on the peak-hour traffic volume in evaluating capacity and other parameters because it represents the most critical time. The analysis of level of service is based on peak rates of flow occurring within the peak hour because substantial short-term fluctuations typically occur during an hour. Common practice is to use a peak 15-minute rate of flow. Flow rates are usually expressed in vehicles per hour, not vehicles per 15 minutes. The relationship between the peak 15-minute flow rate and the full hourly volume is given by the peak-hour factor (PHF) as shown in the following equation (Authority, 2003). Peak-hour factors in urban areas generally range between 0.80 and 0.98 . Peak-hour factors over 0.95 are often indicative of high traffic volumes [32]. PHF was evaluated by the following formula [31].

$\mathrm{PHF}=$ (hourly volume/4* volume count at highest 15-min)

\section{Results and Discussions}

To fulfill the objectives of the study, data analysis has been done on two stages. First, analysis on existing conditions of intersections has been conducted. Secondly, survey data have been conducted to find out the recent traffic performance conditions of these intersections. In mixed traffic condition, modal share is an important factor for assessment of intersection performance. 


\section{Monicottor Intersection}

Moni- Cottor to C \& B lane: It is noticed that most vehicles about 1060 /hour used by public than other vehicles are autorickshaw at evening hour. There is no separate lane constructed for such type of vehicles. Second dominated vehicle is rickshaw and paddle rickshaw and their peak value 359 vehicles/hour and
249 vehicles/hour respectively were found both at afternoon off peak. Afternoon off peak contains maximum number of vehicles in most of the case. Less dominant vehicles are bus, truck, private car, Emma. Moderate dominant vehicles are motor cycle, rickshaw, paddle rickshaw and bi cycle. Their peak value fluctuates at any peak hour (either morning or afternoon peak or evening peak) Figure 6.

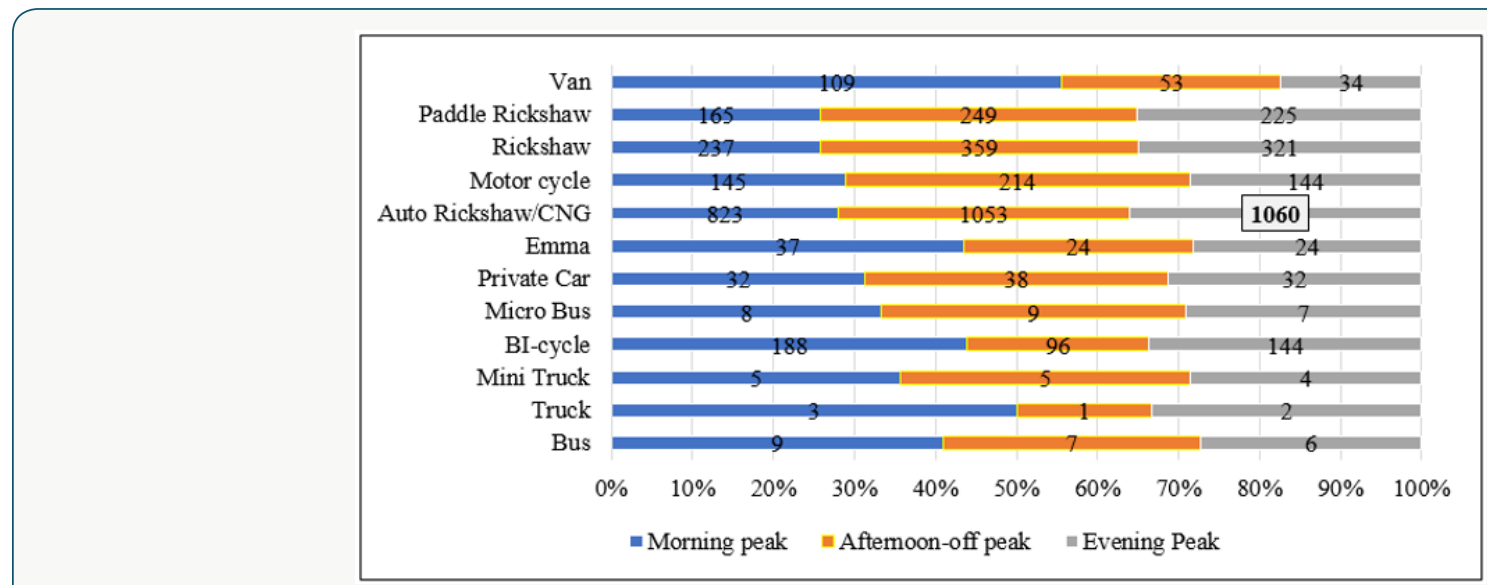

Figure 6: Modal variation of Moni- Cottor to C \& B.

Monicottor to Zero-point lane: In this lane majority of vehicle is auto-rickshaw about 1706 /hour at evening peak. Negligible number of vehicles like bus, mini truck, micro-bus is existing in road. Moderate number of vehicles are paddle rickshaw, motor cycle, rickshaw, van and bi cycle. No truck found in this lane at any peak hour. During evening from 4-6pm maximum amount of traffic is obvious. In this lane traffic volume is so high because traffic flow from three different direction mix here Figure 7.

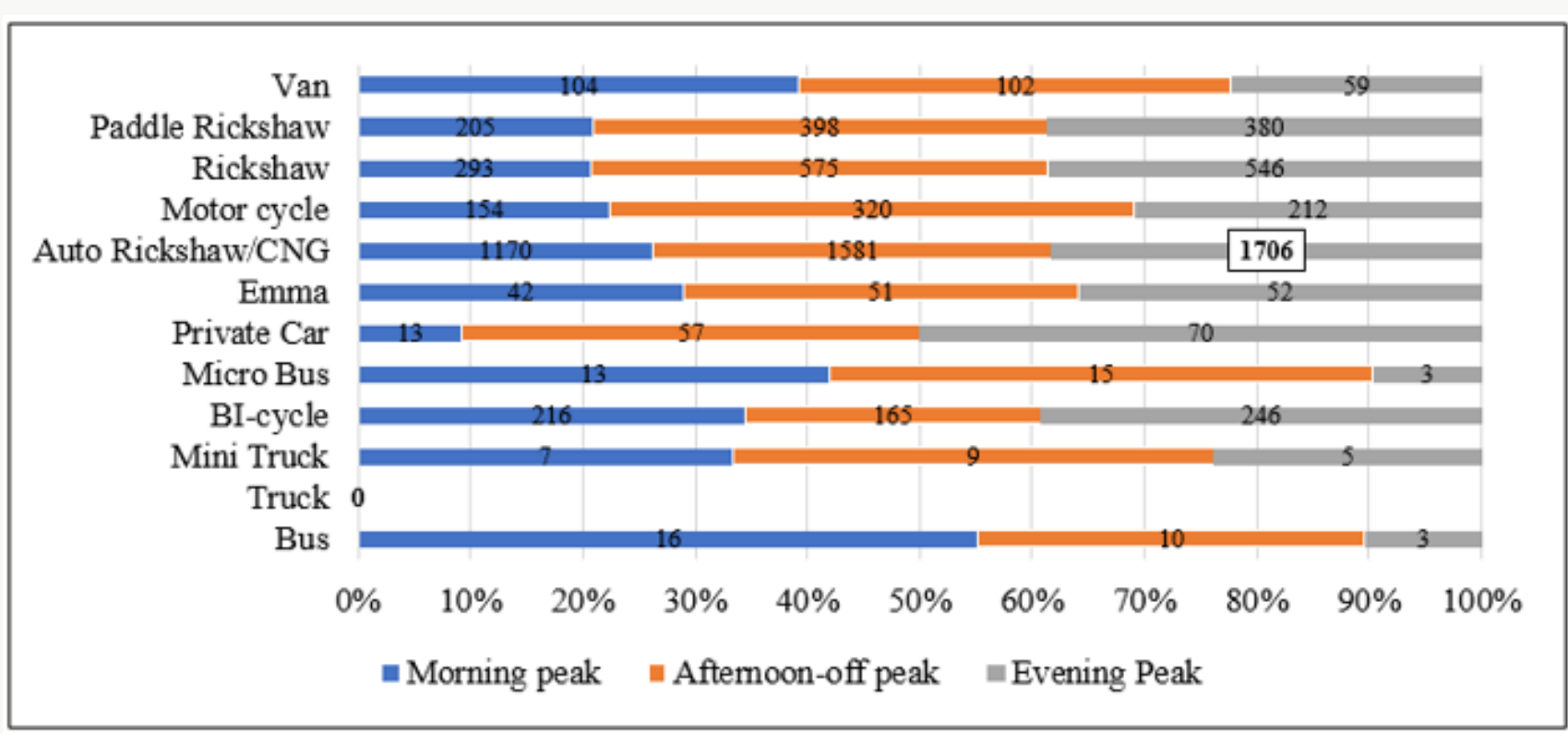

Figure 7: Modal variation of Moni-Cottor to Zero point.

Moni-Cottor to Sonadighi lane: Traffic volume in Sonadighi lane is less than the other lanes. For less carriage width heavy vehicle cannot enter in this lane. Higher amount of Auto-rickshaw or CNG about 160 /hour were found at evening peak. Mainly autorickshaw is dominant vehicle at 3 peaks. No Emma, microbus, truck, bus influence in that lane. Moderate dominant vehicles are motor cycle, rickshaw, paddle rickshaw, bi cycle and van which fluctuate at every peak hours. Vehicles like private car, mini truck are existing in road in less amount Figure 8. 


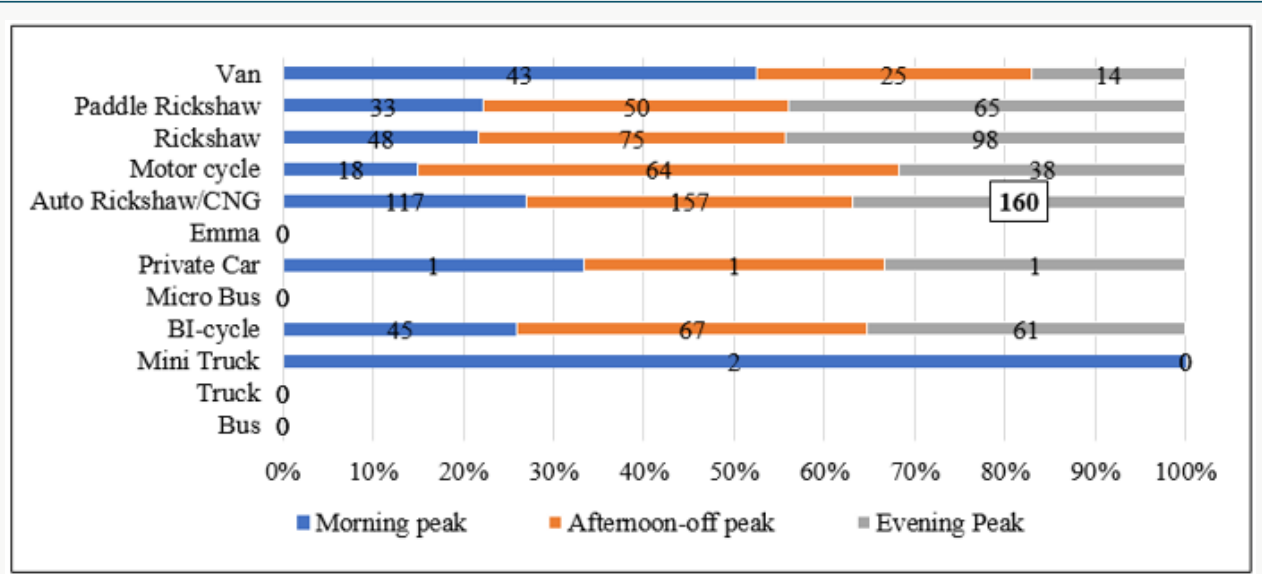

Figure 8: Modal variation of Moni-Cottor to Sonadighi lane.

Temporal Variation of Three legs of Moni-chottor Intersection: Intersection to zero-point leg has $3496 \mathrm{PCU} /$ hour afternoon-off peak. Second one is intersection to zero-point leg and which contains the highest PCU/hour among the three legs at last one is sonadighi leg contain 2242pcu/hour and $452.5 \mathrm{pcu} / \mathrm{hour}$ at afternoon off peak and evening peak respectively Figure 9.

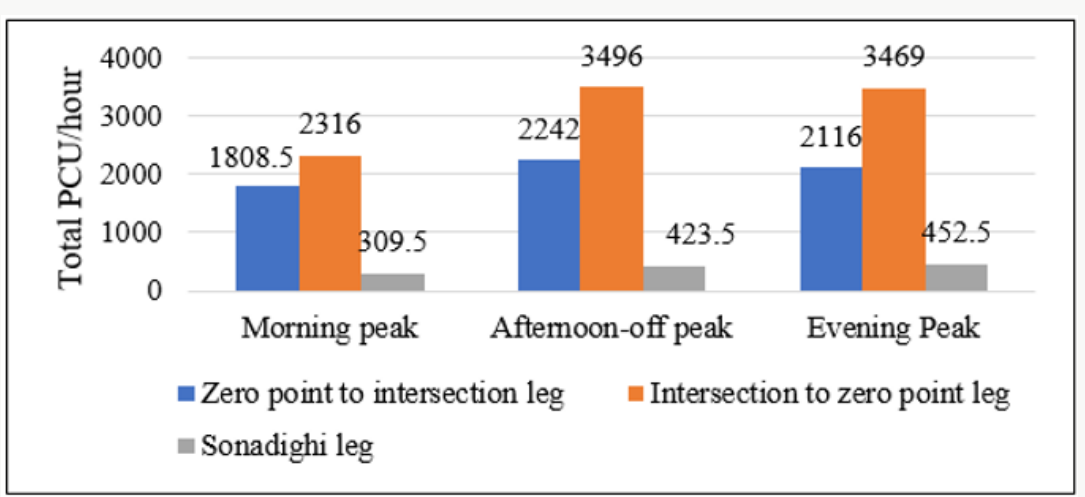

Figure 9: Temporal variation of three legs.

\section{Level of Service in Monicottor Intersection}

\section{V/C Ratio Method}

Analysis shows that in Zero Point to CNB lane \& CNB to Zero Point lane traffic volume is more than its capacity in three periods of time. Only sonadighi lane fell within A category in 3 peaks. Rest of the lanes satisfy level of service of F category. By following $\mathrm{V} / \mathrm{C}$ ratio method LOS of Monicottor intersection is F category in three periods of time Table 4 .

Table 4: Level of service of different lanes of Monicottor intersection by V/C ratio.

\begin{tabular}{|c|c|c|c|c|c|}
\hline \multicolumn{5}{|c|}{ Morning peak } & \multirow{15}{*}{$\mathrm{F}$} \\
\hline Lane Name & Volume (PCU/h) & Capacity & V/C Ratio & LOS & \\
\hline Zero point-CNB Lane & 1808.5 & 1200 & 1.51 & $\mathrm{~F}$ & \\
\hline CNB-Zero point Lane & 2316 & 1200 & 1.93 & $\mathrm{~F}$ & \\
\hline Sonadighi Lane & 309.5 & 2500 & 0.12 & A & \\
\hline \multicolumn{5}{|c|}{ Afternoon peak } & \\
\hline Lane Name & Volume (PCU/h) & Capacity & V/C Ratio & LOS & \\
\hline Zero point-CNB Lane & 2242 & 1200 & 1.87 & $\mathrm{~F}$ & \\
\hline CNB-Zero point Lane & 3496 & 1200 & 2.91 & $\mathrm{~F}$ & \\
\hline Sonadighi Lane & 423.5 & 2500 & 0.17 & A & \\
\hline \multicolumn{5}{|c|}{ Evening peak } & \\
\hline Lane Name & Volume (PCU/h) & Capacity & V/C Ratio & LOS & \\
\hline Zero point-CNB Lane & 2116 & 1200 & 1.76 & $\mathrm{~F}$ & \\
\hline CNB-Zero point Lane & 3469 & 1200 & 2.89 & $\mathrm{~F}$ & \\
\hline Sonadighi Lane & 452.5 & 2500 & 0.18 & A & \\
\hline
\end{tabular}




\section{Peak Hour Factor Method}

Monicottor intersection LOS of Sonadighi lane in morning is E category, in noon LOS of Zero Point to CNB lane \& CNB to Zero Point lane is of D category and in evening peak LOS of the three Table 5: Level of service of different lanes of Moni-cottor intersection by Peak Hour Factor.

\begin{tabular}{|c|c|c|c|c|}
\hline Time & Lane Name & Peak Hour Factor & LOS & \multirow{10}{*}{$\mathrm{E}$} \\
\hline \multirow{3}{*}{ Morning Peak (8 AM-10 AM) } & Zero Point-CNB Lane & 0.65 & $\mathrm{~A}$ & \\
\hline & CNB-Zero Point Lane & 0.71 & $\mathrm{~B}$ & \\
\hline & Sonadighi Lane & 0.91 & $\mathrm{E}$ & \\
\hline \multirow{3}{*}{ Afternoon Off Peak (12 PM- 02PM) } & Zero Point-CNB Lane & 0.88 & $\mathrm{D}$ & \\
\hline & CNB-Zero Point Lane & 0.89 & $\mathrm{D}$ & \\
\hline & Sonadighi Lane & 0.77 & B & \\
\hline \multirow{3}{*}{ Evening Peak (4.30 PM- 6.30 PM) } & Zero Point-CNB Lane & 0.75 & B & \\
\hline & CNB-Zero Point Lane & 0.79 & $\mathrm{~B}$ & \\
\hline & Sonadighi Lane & 0.79 & B & \\
\hline
\end{tabular}

\section{Laxmipur Intersection}

C \& B to Laxmipur: Easy bike is the most dominated vehicle about 489 found in the morning. Rest of the peaks also contain highest amount of easy bike and its amount is 458 and 332 at noon and evening hour respectively. Paddle rickshaw and auto-rickshaw are maximum in afternoon peak period. The maximum volume lanes are category B. As we can see that, among these three periods lowest LOS of Sonadighi lane is category E Table 5. By analyzing two methods level of service of Moni-cottor intersection is F which indicates worse condition exist in this intersection. of motor cycle is found in the evening period whereas maximum private car volume is found in the morning period. Moderate number of vehicles are paddle rickshaw, auto rickshaw, bi cycle. There is no microbus influence in this lane. Less dominant vehicles are truck, van, Mini truck, human holler and also their effect are less at three peaks Figure 10.

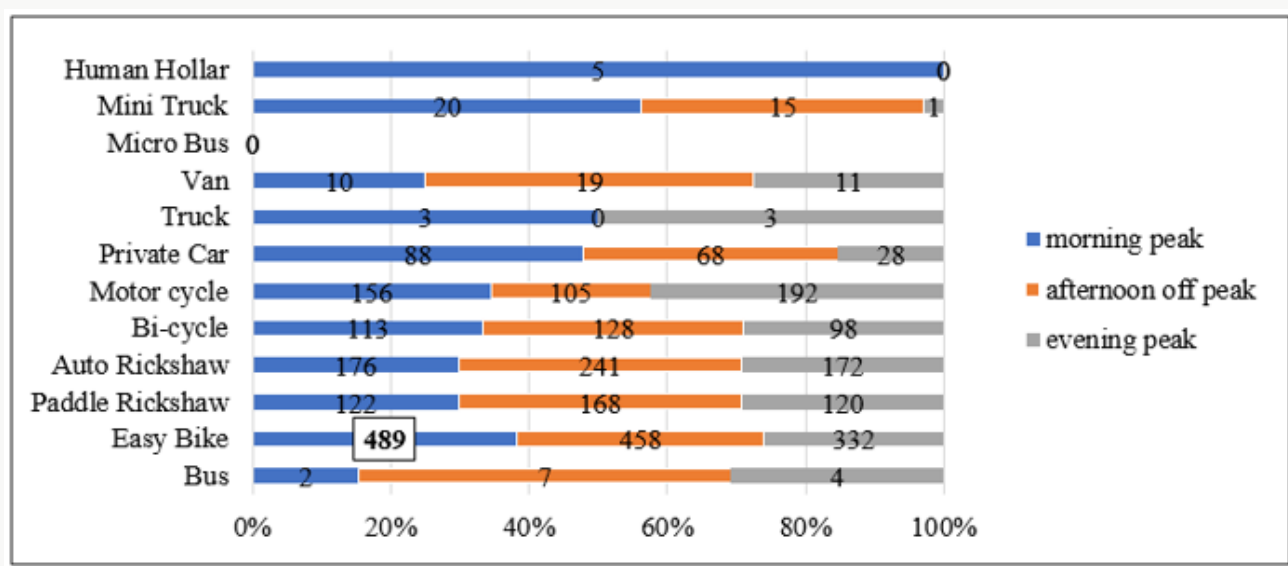

Figure 10: Temporal variation of three legs.

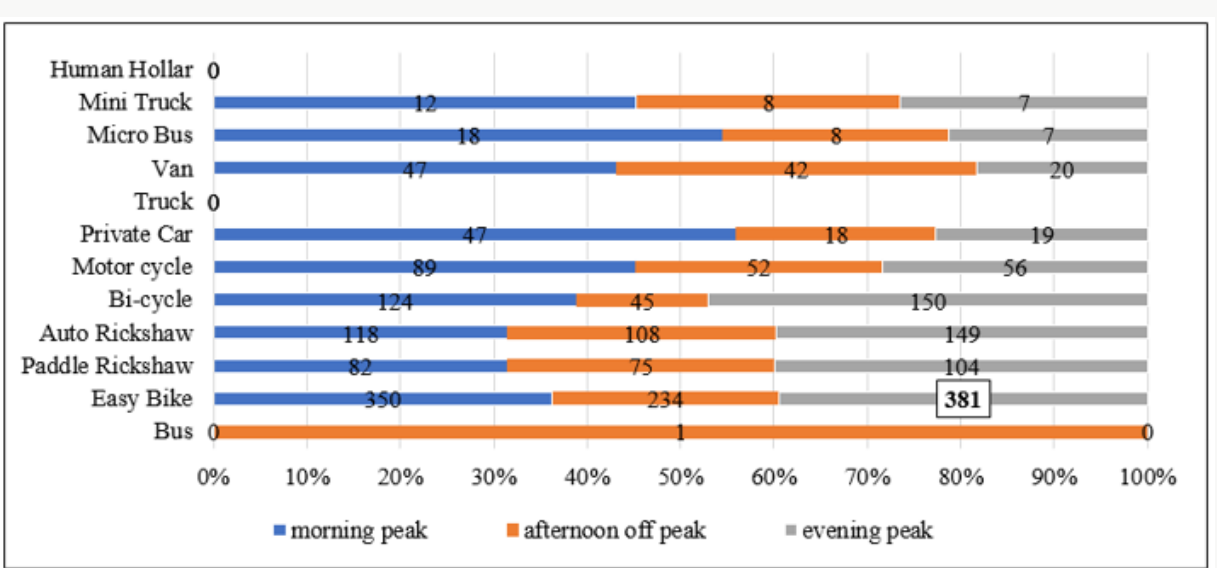

Figure 11: Modal variation of Laxmipur to CNB lane. 
Laxmipur to C \& B lane: High concentration of vehicle in Laxmipur to CNB lane is easy bike. Amount of such type vehicle is 381 was found in evening hour. No truck, human holler influence in this lane. Only one bus was found during afternoon off peak. At evening, morning, afternoon off peaks concentration of auto-rickshaw, paddle rickshaw and bi cycle were maximum. Concentration of van, micro bus, mini truck is limited, their percentages are about $45 \%$, $55 \%$ and $47 \%$ at morning, about $43 \%, 38 \% .40 \%$ at afternoon off peak and rest of the percentage exist at evening respectively Figure 11.
Rail Station to Laxmipur: In This lane, dominant vehicle is easy bike. At morning highest concentration of easy bike was found and its amount is 517. Second dominant vehicles are paddle rickshaw, auto rickshaw, bi cycle, motor cycle, private car and their percentage are about 33\%, 35\%, 59\%, 45\%, 53\% at morning, 35\%, $37 \%, 25 \%, 35 \%, 25 \%$ at afternoon off peak and rest of the percentage of vehicles found at evening respectively. Low volume of traffic like Truck, human holler was found in this lane. Less dominant vehicles were mini truck, micro bus, van and bus Figure 12 .

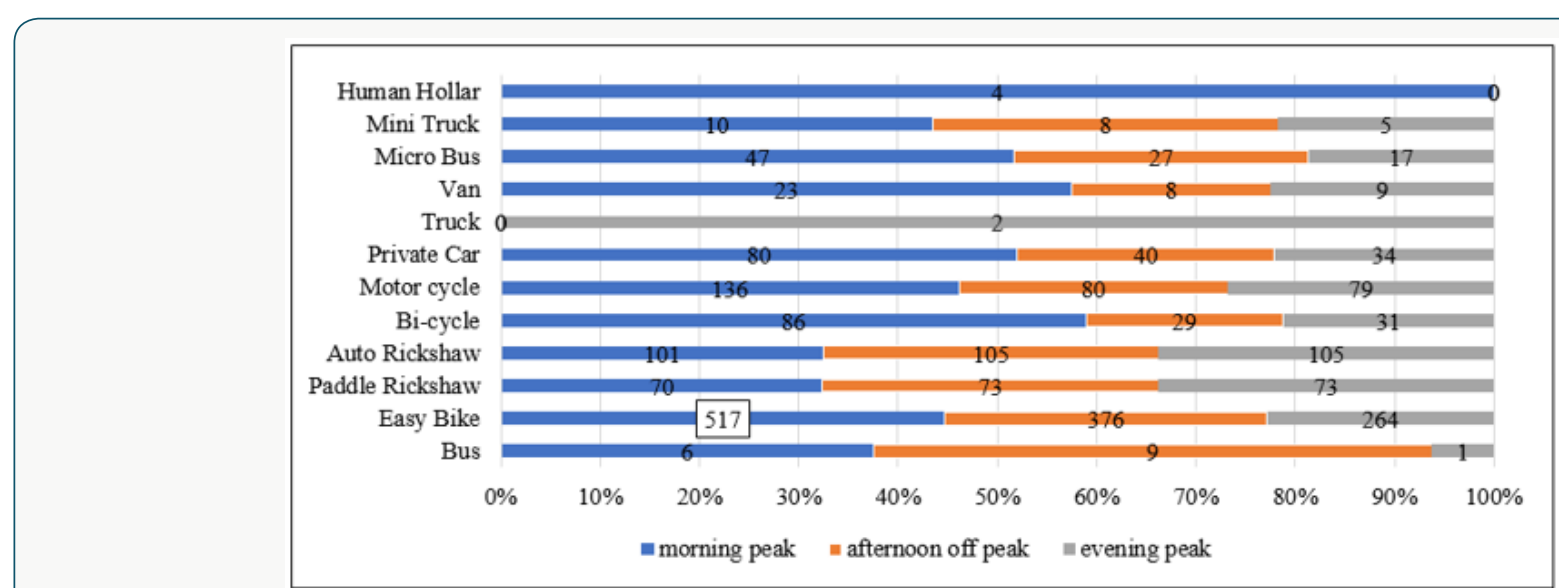

Figure 12: Modal variation of rail station to Laxmipur.

Laxmipur to Rail Station: This lane dominant vehicle is easy bike (536). Less influenced vehicles were truck, bus, van, micro bus, mini truck, and human holler. Concentration of paddle rickshaw, auto rickshaw, bi cycle, motor cycle, private car about 35\%, 37\%,
43\%, 49\%, 49\% at morning, 32\%, 35\%, 39\%, 28\%, 15\% at evening and rest of the percentage vehicles were found at afternoon off peak respectively Figure 13.

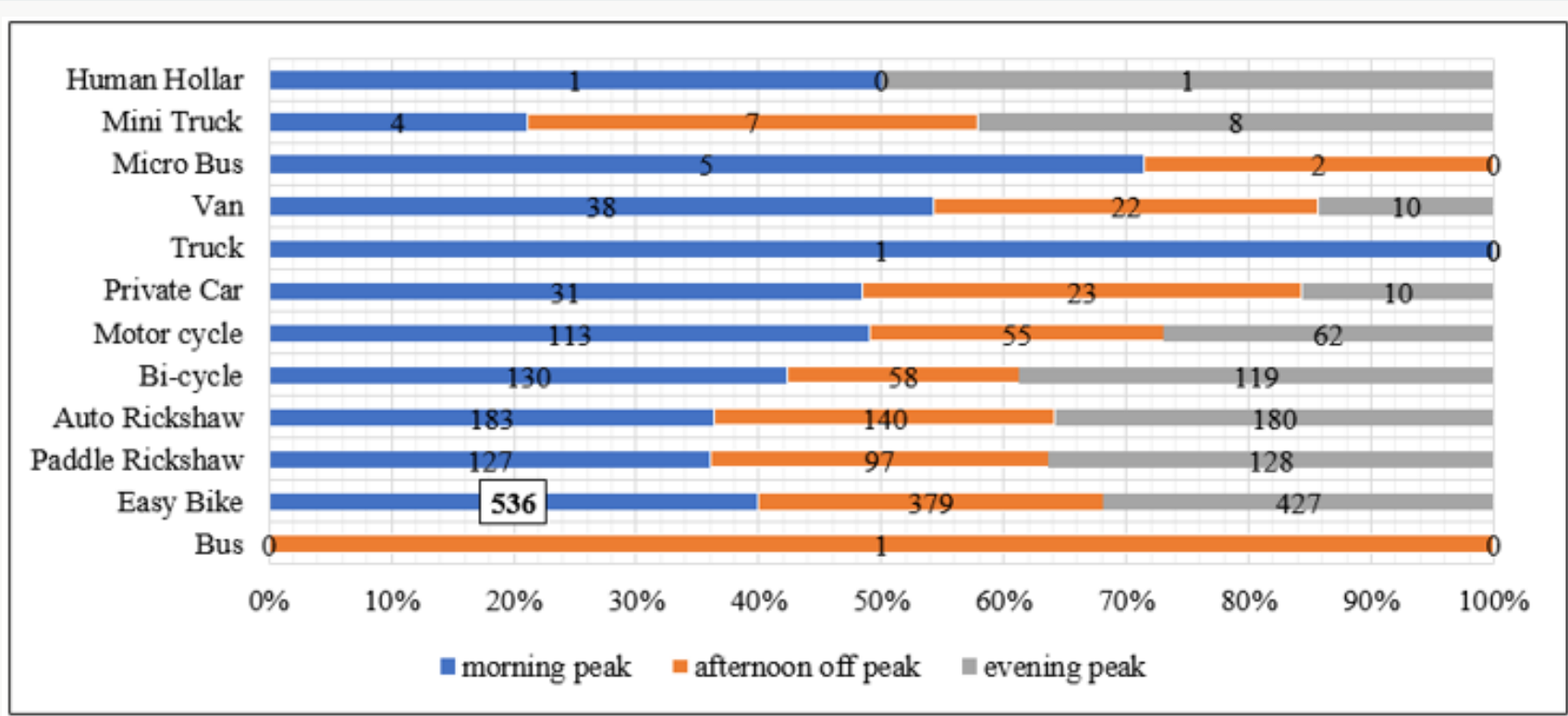

Figure 13: Modal variation of Laxmipur to rail station.

Bazar to Laxmipur: Easy bike dominant at this lane at morning, evening and afternoon off peak. Second dominant vehicles are paddle rickshaw, auto rickshaw, bi cycle, motor cycle, private car and their percentage are approximately 33\%, 34\%, 35\%, 36\%, 32\% at morning, 33\%, 45\%, 45\%, 43\%, 38\%, 28\%. at evening peak and rest of percentage at afternoon off peak respectively. Truck, bus and human holler have no influence. Less volume of vehicles are van, micro bus, and mini truck Figure 14 . 


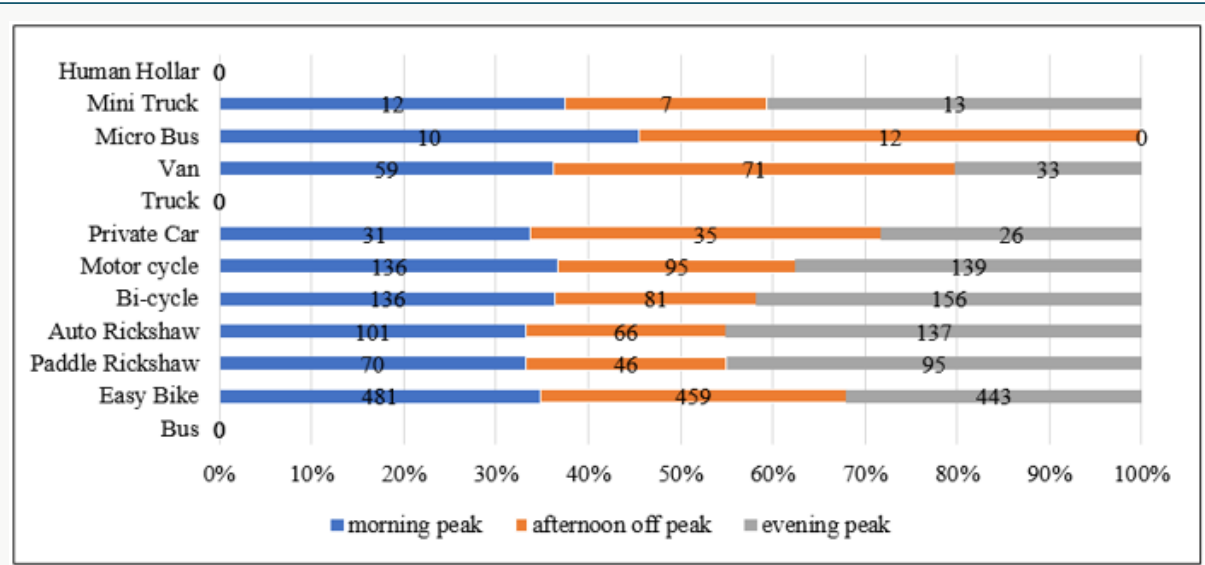

Figure 14: Modal variation of Bazar to Laxmipur.

Laxmipur to Bazar: Easy bike is the dominant vehicle found at morning hour. Second dominant vehicles are paddle rickshaw, auto rickshaw, bi cycle, motor cycle, private car and their concentration percentage are $40 \%, 40 \%, 50 \%, 38 \%$, \& $42 \%$ at morning, $28 \%, 30 \%$, $22 \%, 26 \%, 32 \%$ at afternoon off peak and rest of the percentage at evening peak respectively. Less dominant vehicles are van, micro bus, mini truck, human holler and the concentration of these vehicles fluctuate during evening, morning, and afternoon off peak. Truck has less influence in this lane Figure 15.

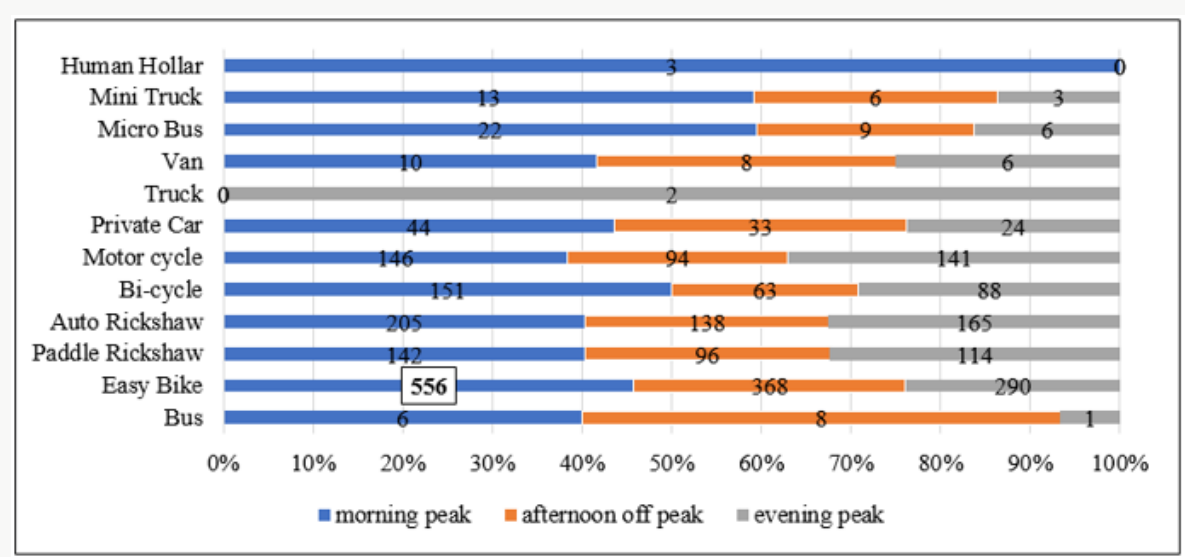

Figure 15: Modal variation of Laxmipur to bazar.

Court to Laxmipur lane: Large amount of vehicles is easy bike found at morning. There is no truck and microbus in this lane. Concentration of paddle rickshaw, auto-rickshaw, bi cycle, motor cycle are $40 \%, 40 \%, 43 \%, 53 \%$ at morning, 23\%, 25\%, 13\%, $22 \%$ at afternoon off peak respectively. Low concentration of vehicles is mini truck, human, holler, private car Figure 16.

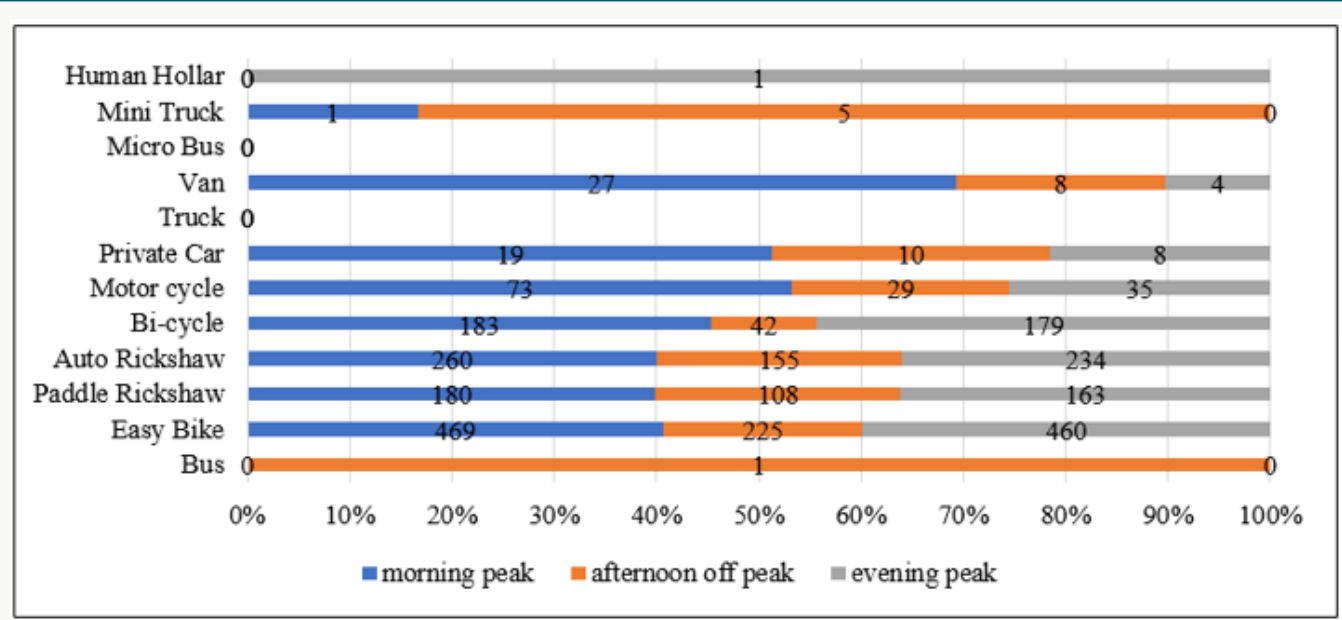

Figure 16: Modal variation of court to Laxmipur lane. 
Laxmipur to Court lane: Large volume of vehicle is easy bike. Human holler was found only morning peak. Percentage of paddle rickshaw, auto rickshaw, bi cycle, motor cycle, and private car are $28 \%, 29 \%$, 35\%, 36\%, 43\%, at morning, 40\%, 42\%, 43\%, 30\%,
$35 \%$, at afternoon off peak respectively. Rest of the percentage was found in evening hour peak. Less influenced vehicles were van, micro bus, mini bus and bus Figure 17.

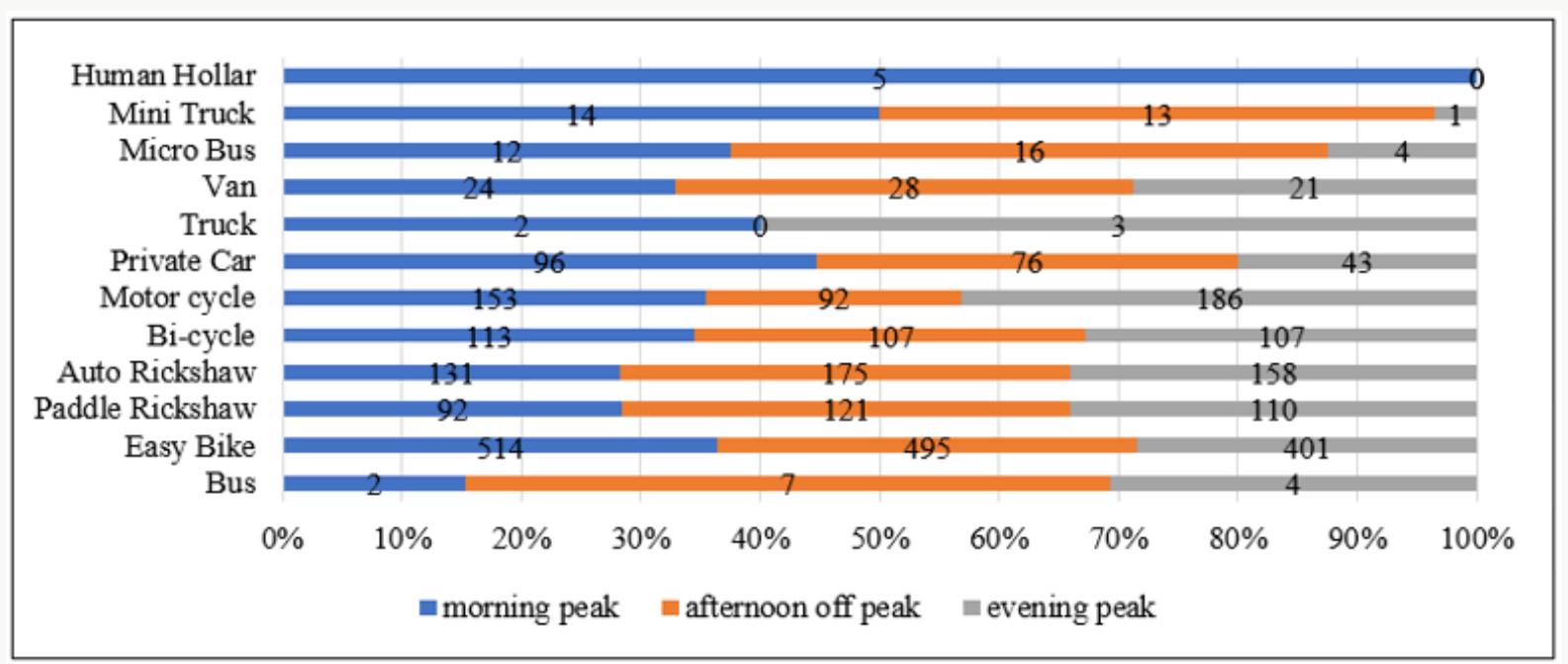

Figure 17: Modal variation of Laxmipur to court lane.

Temporal Variation of Different Legs of Laxmipur Intersection: Laxmipur intersection to bazar leg contain highest amount of PCU/hour at morning hour and this value is 1432.95 PCU/hour. Lowest PCU/hour looked through at Laxmipur intersection to CNB during afternoon off peak. The location of highest concentration of PCU/hour for afternoon off peak and evening were CNB to Laxmipur leg and court to Laxmipur leg respectively.

\section{Level of Service}

V/C Ratio Method: By comparing between given $\mathrm{V} / \mathrm{C}$ ration and standard $\mathrm{V} / \mathrm{C}$ ratio, the highest LOS in respect of $\mathrm{V} / \mathrm{C}$ ratio at morning peak, afternoon off peak, evening peak are $\mathrm{C}, \mathrm{C}$ and $\mathrm{B}$ and their respective locations are Laxmipur to bazar lane, court to Laxmipur lane and Laxmipur to court lane. According to V/C ratio, LOS of Laxmipur intersection is $\mathrm{C}$ by considering all lanes.
Peak Hour Factor Method: According to PHF method the LOS of Laxmipur intersection is F compared to standard PHF. At morning highest PHF is C in CNB to Laxmipur lane, Laxmipur to CNB lane and Laxmipur to court lane. At afternoon off peak, evening peak the highest PHF is F in bazar to Laxmipur lane and Laxmipur to bazar respectively.

By considering and analyzing two methods the LOS of Laxmipur intersection is $\mathrm{F}$ which is worst among all category.

\section{Vodra Intersection}

Talaimari to Vodra: Majority of vehicles in this lane congested during evening. Dominant vehicle is easy bike (temp) which amount is 390 vehicles/hour found at evening. Less influenced vehicles are micro bus, mini truck, mini truck (temp), trolley, CNG, human holler Figure 18,19.

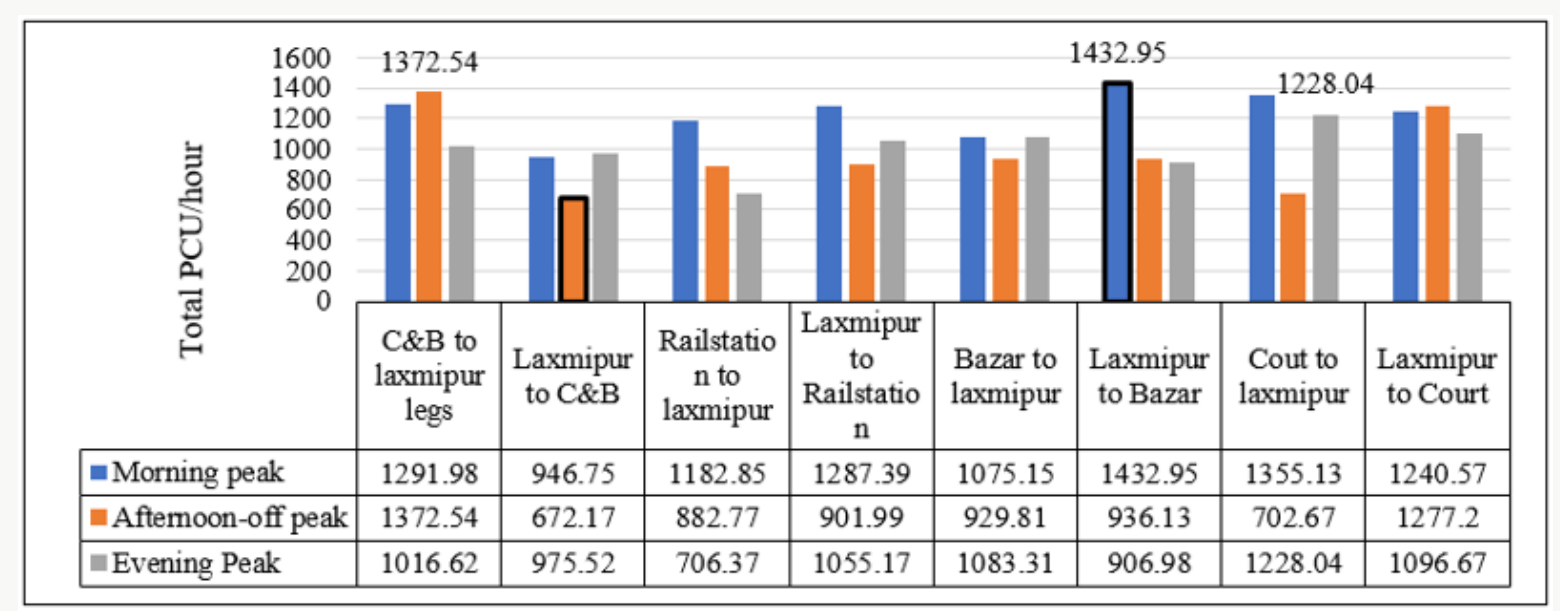

Figure 18: Temporal variation of different of Laxmipur intersection. 


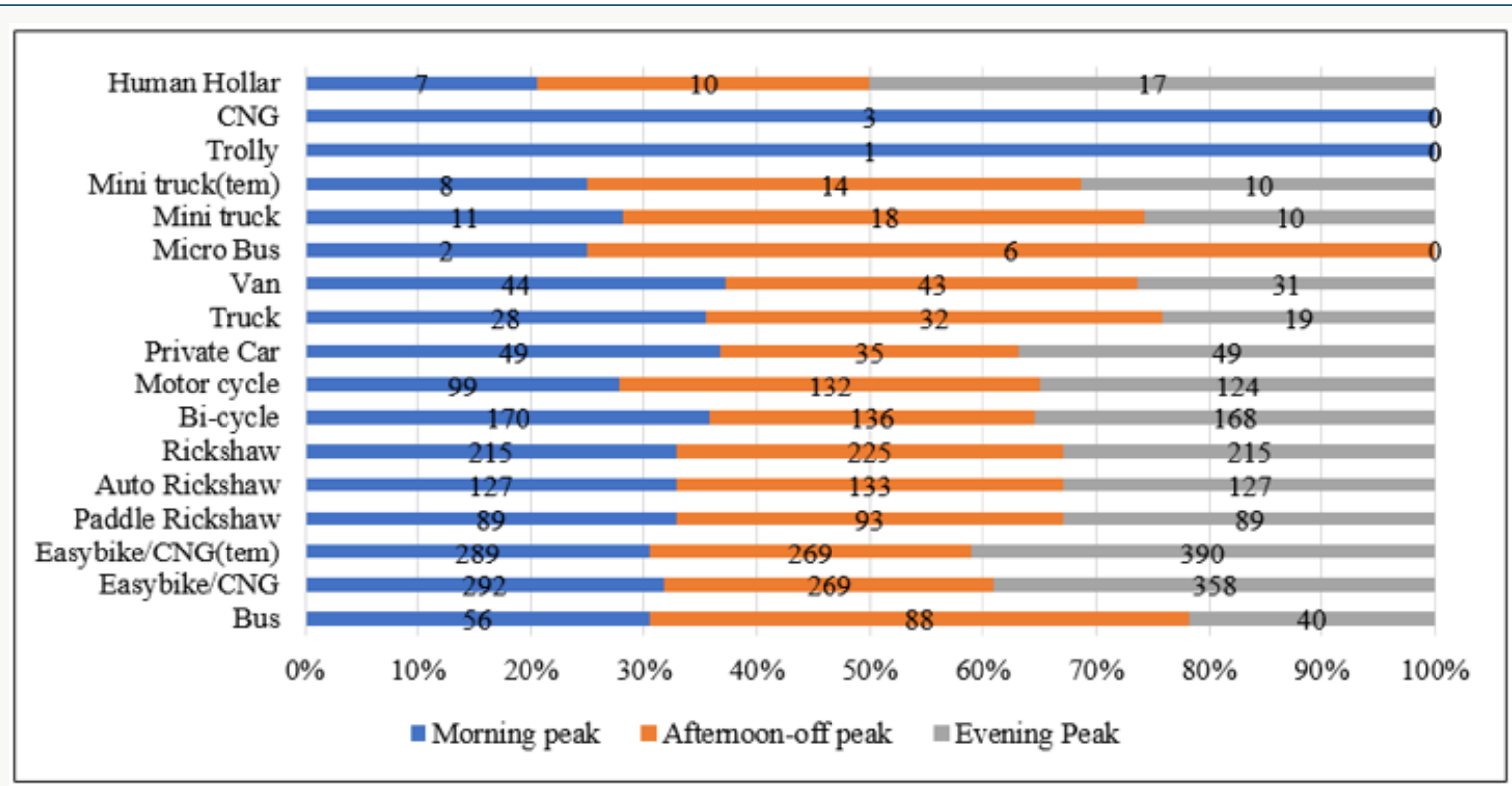

Figure 19: Modal variation of Talaimari to Vodra.

Vodra to Talaimari: Highest concentration of vehicle is 441 vehicle/hour found at evening. Second dominant vehicle is easybike/CNG (temp) which is nearer to first dominant vehicle. Moderate dominant vehicles are paddle rickshaw, auto rickshaw, rickshaw, bicycle, motor cycle, private car and their percentage as well as amounts are $31 \%$ \& $57,32 \%$ \& $87,31 \%$ \& $139,40 \%$ \& 116,
$31 \% \& 91,47 \% \& 45$ at morning, $30 \%$ \& 56, 30\% \& 82, 30\% \& 136, $22 \% \& 69,31 \% \& 91,35 \% \& 34$ at afternoon off peak respectively. Rest of the percentage that is most vehicles congested during evening. Less influenced vehicles are micro bus, van, mini truck, mini truck (temp), trolley, CNG and human holler Figure 20.

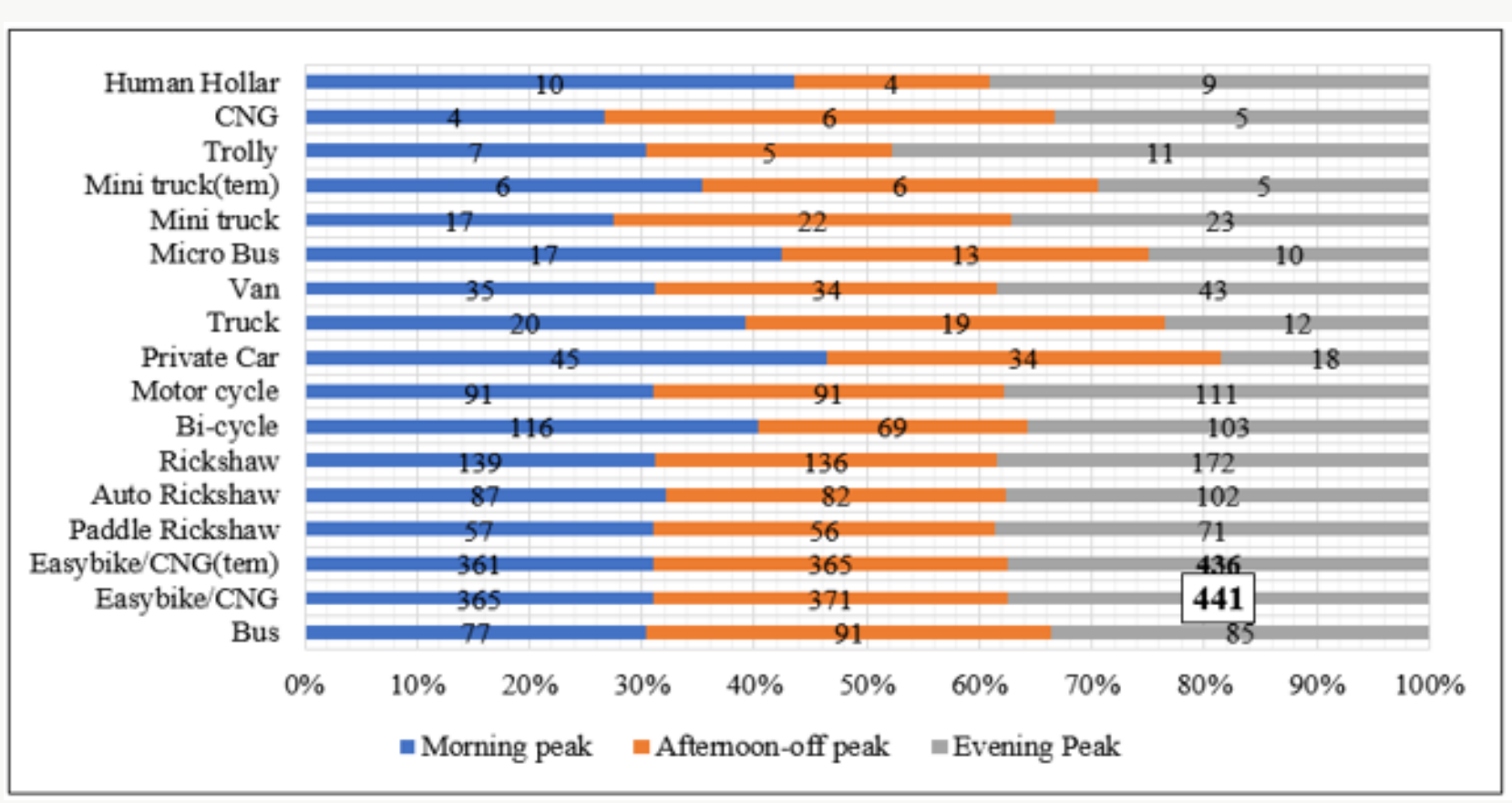

Figure 20: Modal variation of Talaimari to Vodra.

Padma R/A to Vodra: First dominant vehicle is easy bike/ CNG and its concentration is maximum at afternoon off peak. Second dominant vehicle is easy bike/CNG (temp). Concentration of vehicles those are exist in less amount in these lanes are human holler, CNG, trolley, mini truck(temp), micro bus, van, truck and private car. Moderate concentration of vehicles that occupied in this lane are paddle rickshaw, rickshaw, auto rickshaw, bi cycle, motor cycle Figure 21 (Tables 6 \& 7). 
Table 6: Level of service of different lanes of Monicottor intersection by V/C ratio.

\begin{tabular}{|c|c|c|c|c|c|c|}
\hline \multicolumn{5}{|c|}{ Morning peak } & \multirow{10}{*}{$\mathrm{C}$} & \\
\hline Lane Name & Volume (PCU/h) & Capacity & V/C Ratio & LOS & & \\
\hline CNB to Laxmipur lane & 1291.98 & 2000 & 0.65 & $\mathrm{~B}$ & & \\
\hline Laxmipur to CNB lane & 946.75 & 2000 & 0.47 & A & & \\
\hline Railstation to Laxmipur & 1182.85 & 2000 & 0.591425 & A & & \\
\hline Laxmipur to Rail station lane & 1287.39 & 2000 & 0.643695 & $\mathrm{~B}$ & & \\
\hline Bazar to Laxmipur lane & 1075.15 & 2000 & 0.537575 & A & & \\
\hline Laxmipur to bazar lane & 1430.4 & 2000 & 0.716475 & $\mathrm{C}$ & & \\
\hline Court to Laxmipur lane & 1355.13 & 1800 & 0.75285 & $\mathrm{C}$ & & \\
\hline Laxmipur to court lane & 1240.57 & 1800 & 0.689205556 & $\mathrm{~B}$ & & \\
\hline \multicolumn{5}{|c|}{ Afternoon off peak } & \multirow{9}{*}{$\mathrm{C}$} & \\
\hline CNB to Laxmipur lane & 1372.54 & 2000 & 0.68627 & $\mathrm{~B}$ & & \\
\hline Laxmipur to CNB lane & 672.17 & 2000 & 0.336085 & A & & \\
\hline Railstation to Laxmipur & 882.77 & 2000 & 0.441385 & A & & C \\
\hline Laxmipur to Rail station lane & 901.99 & 2000 & 0.450995 & A & & $u$ \\
\hline Bazar to Laxmipur lane & 929.81 & 2000 & 0.464905 & A & & \\
\hline Laxmipur to bazar lane & 936.13 & 2000 & 0.468065 & A & & \\
\hline Court to Laxmipur lane & 702.67 & 1800 & 0.390372222 & A & & \\
\hline Laxmipur to court lane & 1277.2 & 1800 & 0.709555556 & $\mathrm{C}$ & & \\
\hline \multicolumn{5}{|c|}{ Evening peak } & \multirow{9}{*}{ B } & \\
\hline CNB to Laxmipur lane & 1016.62 & 2000 & 0.50831 & A & & \\
\hline Laxmipur to CNB lane & 975.52 & 2000 & 0.48776 & A & & \\
\hline Railstation to Laxmipur & 706.37 & 2000 & 0.353185 & A & & \\
\hline Laxmipur to Rail station lane & 1055.17 & 2000 & 0.527585 & A & & \\
\hline Bazar to Laxmipur lane & 1083.31 & 2000 & 0.541655 & A & & \\
\hline Laxmipur to bazar lane & 906.98 & 2000 & 0.45349 & A & & \\
\hline Court to Laxmipur lane & 1228.04 & 1800 & 0.682244444 & B & & \\
\hline Laxmipur to court lane & 1096.67 & 1800 & 0.609261111 & $\mathrm{~B}$ & & \\
\hline
\end{tabular}

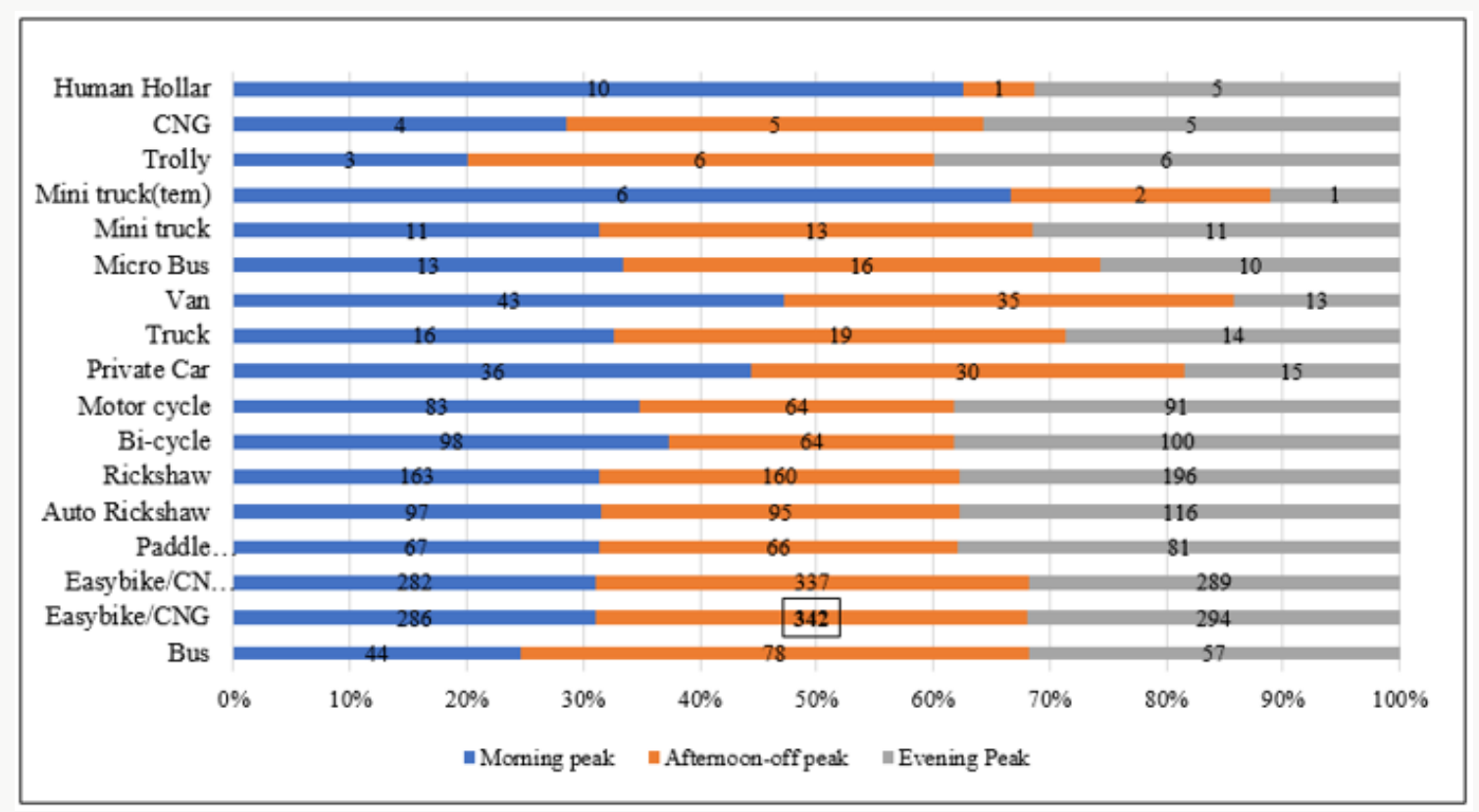

Figure 21: Modal variation of Padma R/A to Vodra. 
Table 7: Level of service of different lanes of Monicottor intersection by Peak hour factor method.

\begin{tabular}{|c|c|c|c|c|c|c|}
\hline \multicolumn{5}{|c|}{ Morning peak } & \multirow{10}{*}{$\mathrm{D}$} & \\
\hline Lane Name & Volume (PCU/h) & 15 min highest PCU & PHF & LOS & & \\
\hline CNB to Laxmipur lane & 1291.98 & 399.53 & 0.81 & $\mathrm{C}$ & & \\
\hline Laxmipur to CNB lane & 946.75 & 280.31 & 0.84 & $\mathrm{C}$ & & \\
\hline Railstation to Laxmipur & 1182.85 & 523.21 & 0.57 & A & & \\
\hline Laxmipur to Rail station lane & 1287.39 & 410.11 & 0.78 & B & & \\
\hline Bazar to Laxmipur lane & 1075.15 & 370.89 & 0.72 & $\mathrm{~B}$ & & \\
\hline Laxmipur to bazar lane & 1430.4 & 416.2 & 0.74 & B & & \\
\hline Court to Laxmipur lane & 1355.13 & 394.69 & 0.86 & $\mathrm{D}$ & & \\
\hline Laxmipur to court lane & 1240.57 & 381.85 & 0.81 & $\mathrm{C}$ & & \\
\hline \multicolumn{5}{|c|}{ Afternoon off peak } & \multirow{9}{*}{$\mathrm{F}$} & \\
\hline CNB to Laxmipur lane & 1372.54 & 385.3 & 0.89 & $\mathrm{D}$ & & \\
\hline Laxmipur to CNB lane & 672.17 & 193.01 & 0.87 & $\mathrm{D}$ & & \\
\hline Railstation to Laxmipur & 882.77 & 327.88 & 0.67 & A & & $\Gamma$ \\
\hline Laxmipur to Rail station lane & 901.99 & 239.66 & 0.94 & E & & $\Gamma$ \\
\hline Bazar to Laxmipur lane & 929.81 & 242.73 & 0.96 & $\mathrm{~F}$ & & \\
\hline Laxmipur to bazar lane & 936.13 & 354.02 & 0.66 & A & & \\
\hline Court to Laxmipur lane & 702.67 & 240.57 & 0.73 & B & & \\
\hline Laxmipur to court lane & 1277.2 & 356.97 & 0.89 & $\mathrm{D}$ & & \\
\hline \multicolumn{5}{|c|}{ Evening peak } & \multirow{9}{*}{$\mathrm{F}$} & \\
\hline CNB to Laxmipur lane & 1016.62 & 302.27 & 0.85 & $\mathrm{C}$ & & \\
\hline Laxmipur to CNB lane & 975.52 & 266.09 & 0.92 & $\mathrm{E}$ & & \\
\hline Railstation to Laxmipur & 706.37 & 206.84 & 0.86 & $\mathrm{D}$ & & \\
\hline Laxmipur to Rail station lane & 1055.17 & 344.65 & 0.77 & B & & \\
\hline Bazar to Laxmipur lane & 1083.31 & 288.06 & 0.95 & E & & \\
\hline Laxmipur to bazar lane & 906.98 & 231.45 & 0.98 & $\mathrm{~F}$ & & \\
\hline Court to Laxmipur lane & 1228.04 & 390.08 & 0.79 & B & & \\
\hline Laxmipur to court lane & 1096.67 & 1800 & 0.94 & E & & \\
\hline
\end{tabular}

Vodra to Padma R/A: Highest concentration of vehicles are CNG, trolley, mini truck, micro bus, van, and truck. Moderate in this lane are easy bike/CNG and easy bike/CNG (temp) and concentration of vehicles are paddle rickshaw, auto rickshaw, contained same amount. Concentration was maximum at evening rickshaw, bi cycle, motor cycle Figure 22.

in case of both types of vehicles. Less concentration of vehicles

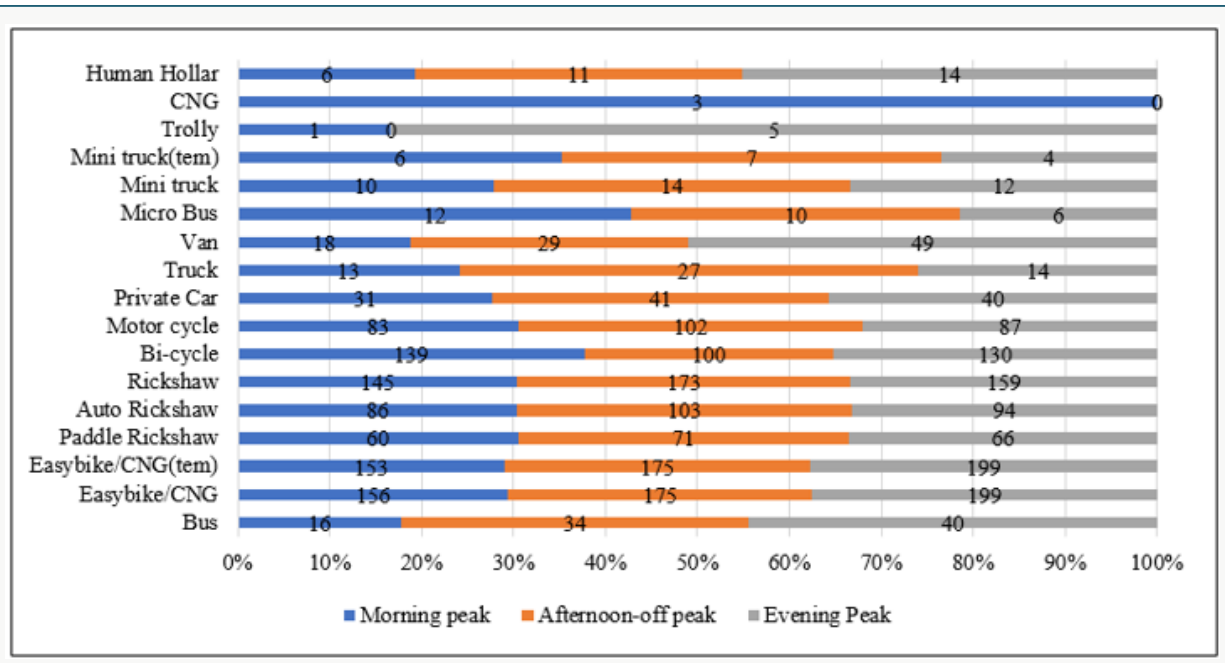

Figure 22: Modal variation of Vodra to Padma R/A. 
Rail gate to Vodra: Highest concentration of vehicles in this lane are easy bike/CNG and easy bike/CNG (temp) and contained same amount. Concentration was maximum at evening in case of both types of vehicles. Less concentration of vehicles are human holler, CNG, trolley, mini truck, micro bus, van, truck, private car. Moderate concentration of vehicles are paddle rickshaw, auto rickshaw, rickshaw, bi cycle, motor cycle Figure 23.

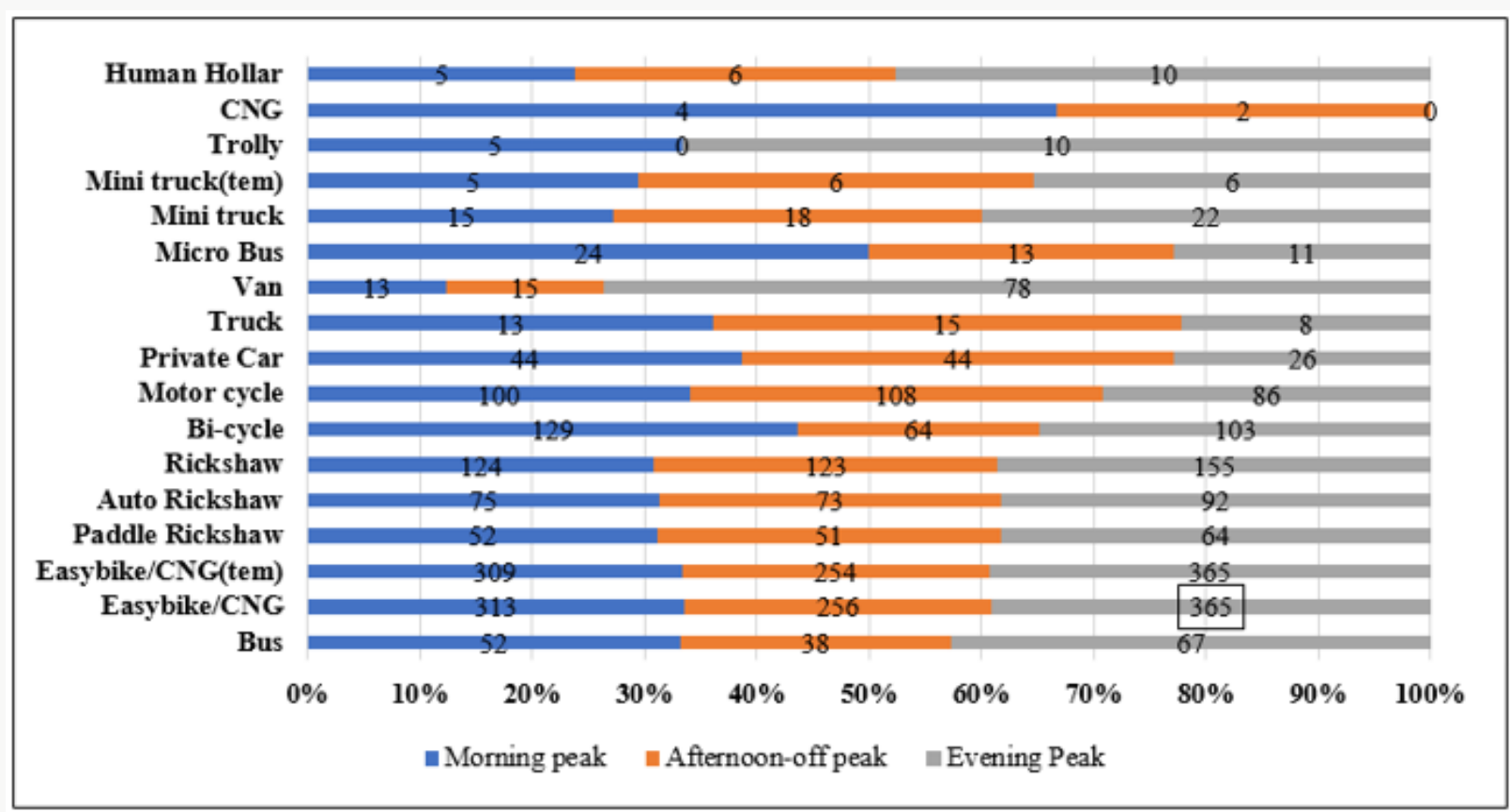

Figure 23: Modal variation of Railgate to Vodra.

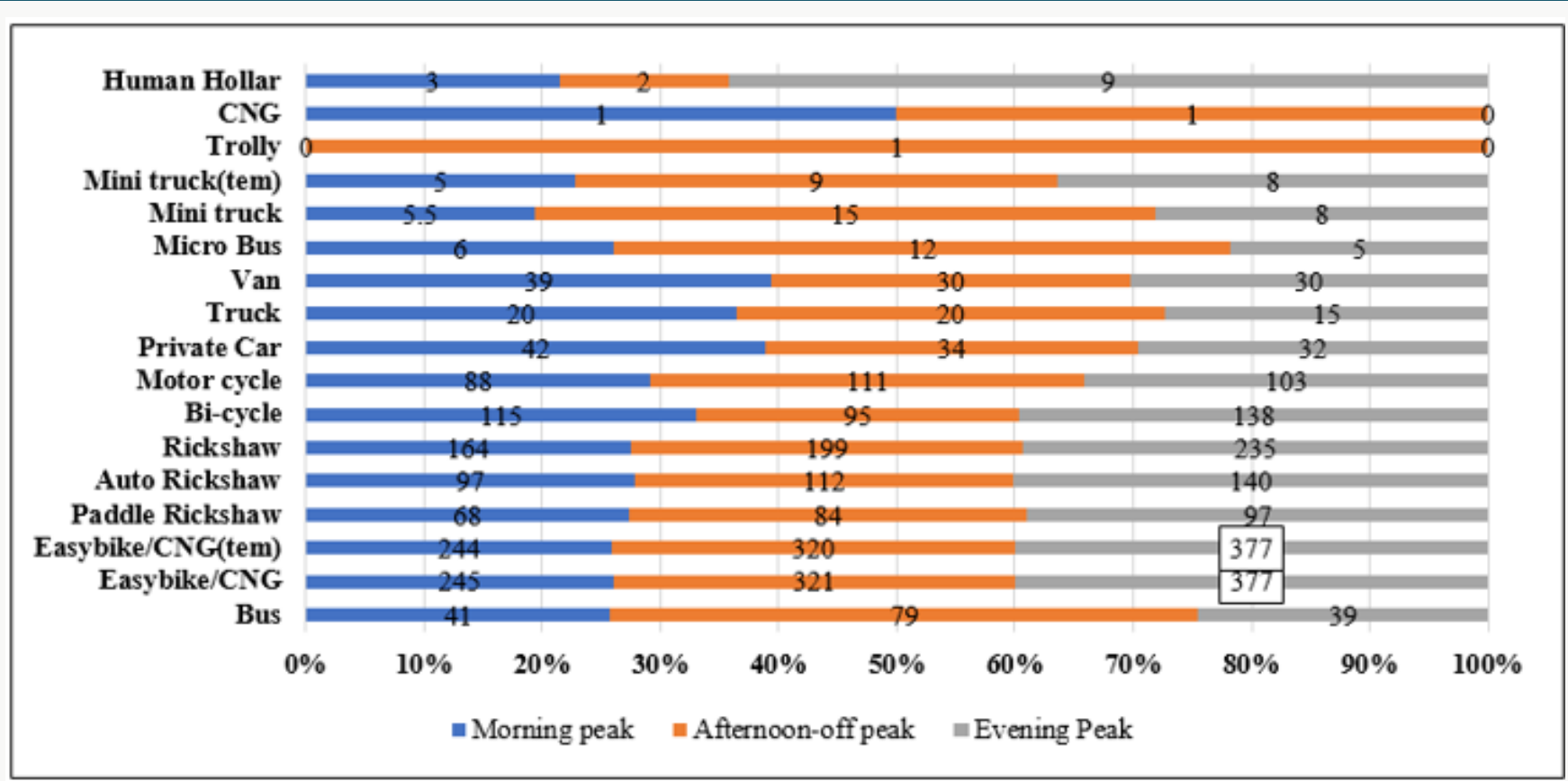

Figure 24: Modal variation of Vodra to railgate.

Vodra to rail gate lane: This lane also follows previous two lanes Railgate to Vodra, Vodra to Padma R/A Figure 24.

Temporal Variation of Different Legs: Concentration of volume in case of Vodra to Talaimari lane was high at evening peak.
All lanes have highest PCU/hour at evening peak except Vodra to Talaimari lane. The lowest PCU/hour was 1426.93 found in Vodra to paddma R/A during morning peak Figure 25. 


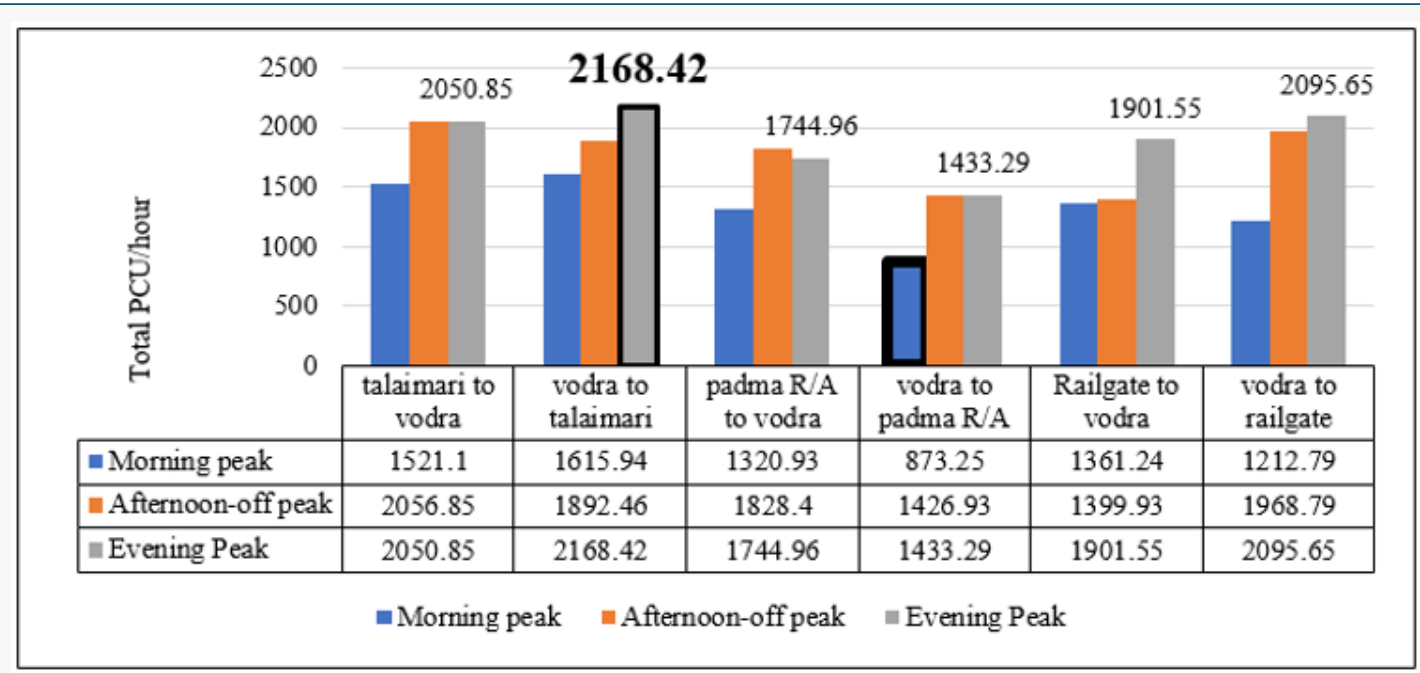

Figure 25: Temporal variation of Vodra intersection.

\section{Level of Service}

V/C Ratio Method: The volume of Vodra to Padma R/A lane, Padma R/A to Vodra, are higher than

Table 8: Level of service of different lanes of Monicottor intersection by V/C Ratio Method.

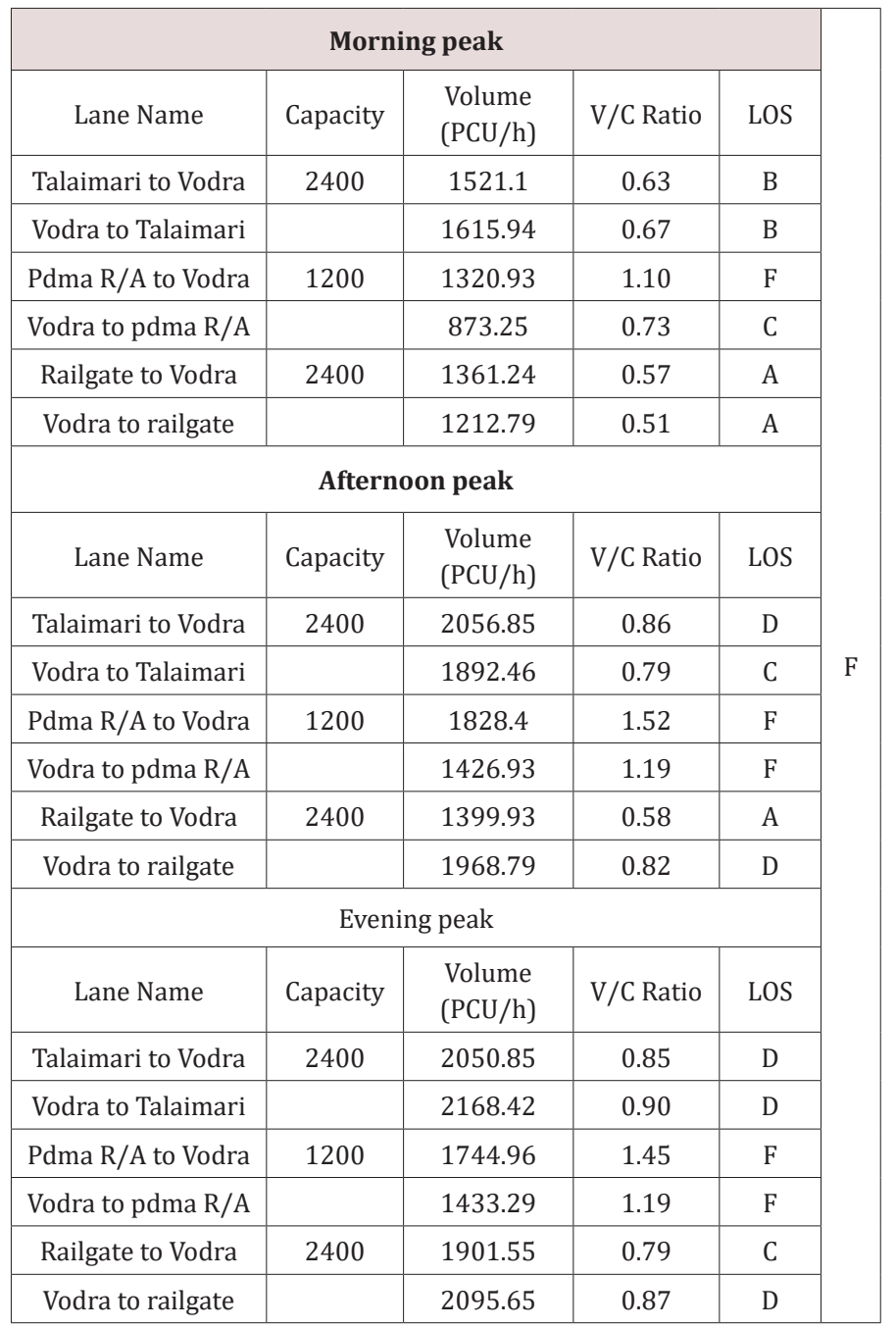

Table 9: Level of service of different lanes of Monicottor intersection by Peak hour factor method.

\begin{tabular}{|c|c|c|c|c|c|c|}
\hline \multicolumn{6}{|c|}{ Morning peak } & \\
\hline Lane Name & Capacity & $\begin{array}{l}\text { Volume } \\
(\mathrm{PCU} / \mathrm{h})\end{array}$ & $\begin{array}{c}15 \mathrm{~min} \\
\text { highest } \\
\text { PCU }\end{array}$ & PHF & LO & \\
\hline Talaimari to Vodra & 2400 & 1427.6 & 384.044 & 0.82 & $\mathrm{C}$ & \\
\hline Vodra to Talaimari & & 1182.5 & 422.22 & 0.82 & $\mathrm{C}$ & \\
\hline $\begin{array}{l}\text { Pdma R/A to } \\
\text { Vodra }\end{array}$ & 1200 & 868.25 & 378.754 & 0.85 & $\mathrm{C}$ & \\
\hline $\begin{array}{c}\text { Vodra to pdma } \\
\text { R/A }\end{array}$ & & 1162.6 & 326.862 & 0.67 & A & \\
\hline Railgate to Vodra & 2400 & 1139.4 & 368.422 & 0.91 & $\mathrm{E}$ & \\
\hline Vodra to railgate & & 1119.5 & 417.664 & 0.72 & B & \\
\hline \multicolumn{6}{|c|}{ Afternoon peak } & \\
\hline Talaimari to Vodra & 2400 & 1438.1 & 384.044 & 0.94 & $\mathrm{E}$ & \\
\hline Vodra to Talaimari & & 1306.1 & 422.22 & 0.77 & B & \\
\hline $\begin{array}{l}\text { Pdma R/A to } \\
\text { Vodra }\end{array}$ & 1200 & 1397.5 & 378.754 & 0.92 & E & \\
\hline $\begin{array}{c}\text { Vodra to pdma } \\
\text { R/A }\end{array}$ & & 1126.6 & 326.862 & 0.86 & $\mathrm{D}$ & \\
\hline Railgate to Vodra & 2400 & 1133.7 & 368.422 & 0.77 & B & \\
\hline Vodra to railgate & & 1286.8 & 417.664 & 0.77 & B & \\
\hline \multicolumn{6}{|c|}{ Evening peak } & \\
\hline Talaimari to Vodra & 2400 & 1517.4 & 456.116 & 0.83 & $\mathrm{C}$ & \\
\hline Vodra to Talaimari & & 1449.3 & 430.272 & 0.84 & C & \\
\hline $\begin{array}{l}\text { Pdma R/A to } \\
\text { Vodra }\end{array}$ & 1200 & 1214.9 & 385.676 & 0.79 & B & \\
\hline $\begin{array}{c}\text { Vodra to pdma } \\
\text { R/A }\end{array}$ & & 1246.5 & 338.300 & 0.92 & $\mathrm{E}$ & \\
\hline Railgate to Vodra & 2400 & 1131 & 313.806 & 0.90 & $\mathrm{E}$ & \\
\hline Vodra to railgate & & 1314.9 & 367.696 & 0.89 & D & \\
\hline
\end{tabular}

capacity during three peaks. The highest LOS of Vodra intersection is $\mathrm{F}$ by following $\mathrm{V} / \mathrm{C}$ ratio Table 8 . LOS identified by PHF was E. Vodra to Padma R/A, Railgate to Vodra, Talaimari to 
Vodra contain highest LOS at evening, morning and afternoon off peak respectively. The final LOS in this intersection is F Table 9.

\section{Dissuasion}

\section{Causes of Congestion in Intersection}

Moni-chottor intersection plays as a main commercial hub of Rajshahi city. This is the main reason of rising auto-rickshaw volume in Moni-chottor intersection. Traffic flow in afternoon off-peak is higher than other two peak hours. This is may be due to Monichottor intersection is located near educational zone. The factors for greater traffic flow from Zero point to Intersection is the land use containing important establishments like Rajshahi Collegiate School and College, Rajshahi College, a large Kaccha Bazar, Janata Bank Corporate Bank, etc. As the effective carriageway width is only 12 feet, the LOS of these two lanes is F. Less rent and quickly reached in destination are one of the major reason to get the majority and popularity of increase amount of auto-rickshaw [3]. Some probable reasons behind the fascination of using CNG by operators as well as passengers were investigated. Attractive advantages like Reduction of maintenance cost, emissions of 20-30\% fewer greenhouse gas, environmentally friendly behavior, superior to petroleum-based products diverted and motivated the operators to use such type of vehicles [33].

\section{Effect of Congestion in intersection}

One of the major disadvantage is uncontrolled or non-signalized intersections. This is also known as priority-controlled intersection. It provides no indication to the driver's concern when vehicle

\section{Comparison of Three Intersections}

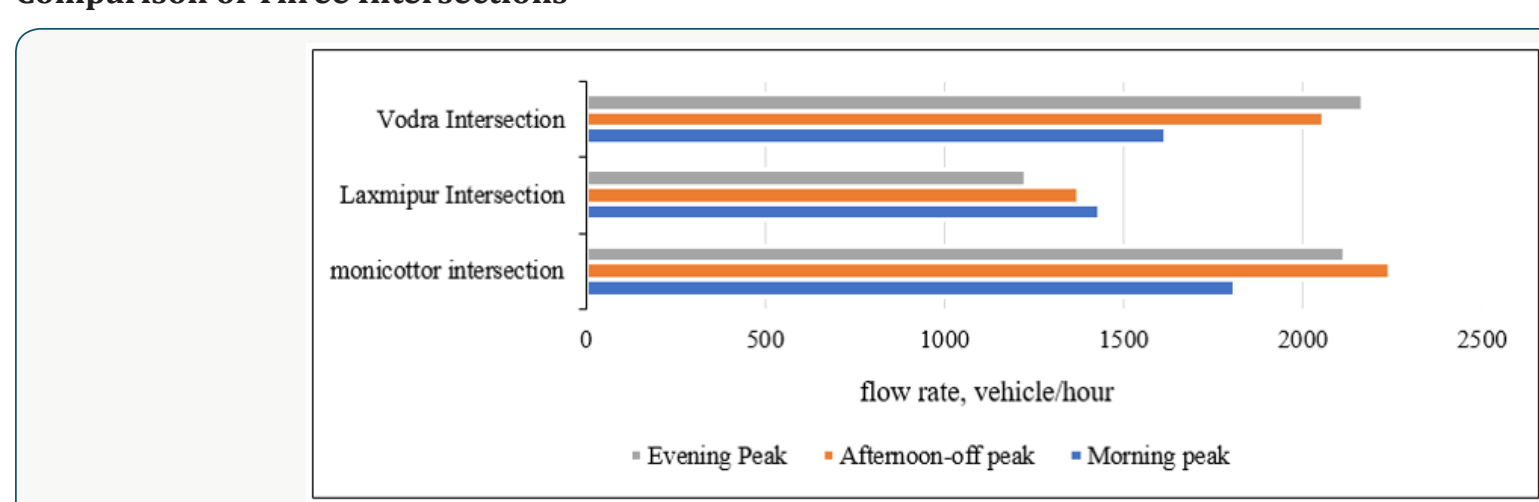

Figure 26: Comparison of flow rates of three intersections.

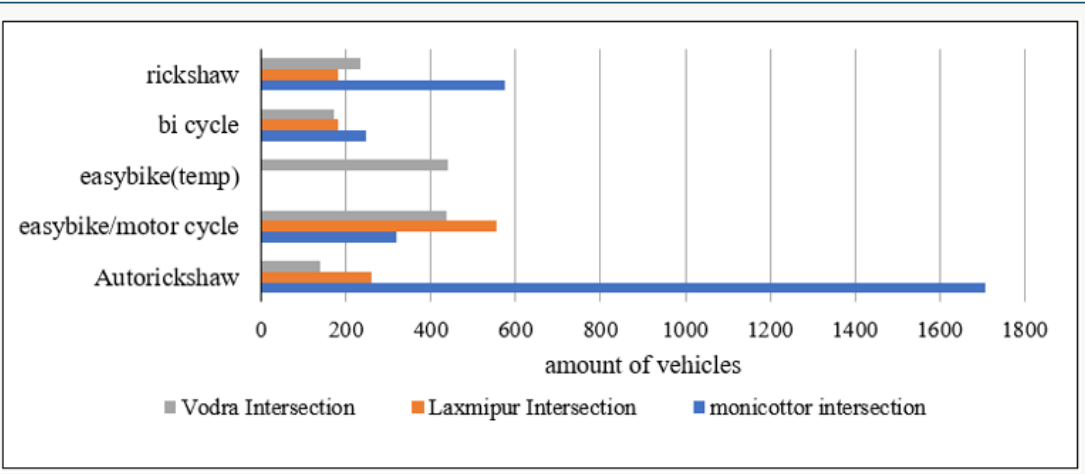

Figure 27: Major (dominant) number of vehicles at different intersections. 
Flow rate of vehicle is maximum at monicottor at three peaks. Second one is Vodra intersection. Lowest peak was observed at Laxmipur intersection among all Figure 26. By inspecting selected intersections, the major or dominant vehicle is auto rickshaw in monicottor. That's why, this is the more congestive intersection. The influence of easybike (temp) only dominant in Vodra intersection. Second dominant vehicle is easy bike or motor cycle Figure 27.

\section{Conclusion}

The traffic flow behavior in heterogeneous traffic in Rajshahi city is observed that is absolutely complex. Highest concentration of dominant vehicle (easy bike/CNG) is found in the morning peak period (12 pm-2 pm) at Laxmipur to bazar determined by using modal variation. Laxmipur intersection to bazar leg contain highest amount of PCU/hour at morning hour by using temporal variation. According to $\mathrm{V} / \mathrm{C}$ ratio and PHF the LOS are $\mathrm{C}$ and $\mathrm{F}$ respectively. The final LOS of Laxmipur intersection is $\mathrm{F}$. In case of Vodra intersection, highest concentration of vehicles are easy bike/CNG and easybike (temp) found in all lane. The maximum road space are covered by easy bike. Evening peak contains large volume of vehicles determined by using temporal variation. Vodra to Talaimari lane contain large amount of volume during evening. The existing volume of Padma R/A to Vodra lane at morning, Padma R/A to Vodra lane, Vodra to pdma R/A lane at afternoon off peak and evening peak are higher than their standard capacity. LOS of this intersection is F. At monicottor intersection, auto rickshaw is the dominant vehicle in all lanes. Traffic flow in afternoon off-peak is higher than other two peak hours in CNB-Zero point because traffic flow from different three direction mix here. The volume of CNBZero point lane, Zero point to CNB lane at afternoon off peak and morning are higher than their standard capacity. According to Peak Hour Factor Method, LOS of Monicottor intersection is E category at its highest peak. According to V/C ratio method, LOS of Monicottor intersection is F category. So, final LOS is F. Carriageway width should be increased. Local Govt. authority should take necessary steps to improve the condition of these selected intersection.

\section{References}

1. Ashish Kumer Saha, BA, Motiur Rahman, Tahmina Tasnim Nahar (2013) Analysis of Traffic Congestion and Remedial Measures at Traffic Mor in Pabna City, Bangladesh International Journal of Recent Development in Engineering and Technology 1(2): 23-26.

2. Imran MAA, Ahmed B, Bhuiyan MK (2014) Investigation of highway geometric problems and remedial measures in Rajshahi City corporation area, Bangladesh International Journal of Advanced Structures and Geotechnical Engineering 3(2): 126-133.

3. Rabeya Basri, TK, Md Selim Reza, M Moazzem Hossain Khan (2014) Changing Modes of Transportation: A Case Study of Rajshahi City Corporation.

4. Malik FA, Lone MA, Qasab RA, Gul M (2016) Traffic Census And Analysis (A Case Study). International Journal of Research in Engineering and Technology 5(3): 69-76.

5. Rawid (1995) TrafficVolumeStudies.

6. A Mehar, SC, SV (2014) Passenger Car Units at Different Levels of Service for Capacity Analysis of Multilane Interurban Highways in India. Journal of Transportation Engineering 140(1): 81-88.
7. V Thamizh Arasan, PV (2006) Estimation Of Saturation Flow Of Heterogeneous Traffic Using Computer Simulation. European Conference on Modelling and Simulation.

8. Authority, SCCT (2003) Traffic Level Of Service Analysis Guidelines.

9. Shah PM, Gupta N (2016) Study of Traffic Flow Characteristics on the National Highway (NH1) Connecting Jalandhar-Phagwara Internationation journal of Latest Trends in Engineering and Technology 6(4): 51-61.

10. Mathew DTV (2014) Capacity and Level of Service LOS Transportation Systems Engineering. IIT Bombay. p. 21-25.

11. Level of Service Standard and Measurements (2016) pp. 391-394.

12. Haque A (2008) Transport Situation in Rajshahi.

13. MR Haque, MAR, MB Hossain, M Roknuzzaman (2017) Capacity Evaluation of Roundabout Intersections in Khulna Metropolitan City by Using SIDRA. International Conference on Planning, Architecture and Civil Engineering, Rajshahi, Bangladesh.

14. Bui K-HN, Camacho D, Jung J E (2017) Real-Time Traffic Flow Management Based on Inter-Object Communication: a Case Study at Intersection. Mobile Netw Appl 22(4): 613-624.

15. Farooq, D, Akram T (2017) Traffic Flow Analysis and Solutions to Ease Traffic Flow at Unsignalized Taxila Intersection. Periodica Polytechnica Transportation Engineering 46(2): 101-107.

16. Li J, Yue Z, Wong S (2004) Performance evaluation of signalized urban intersections under mixed traffic conditions by gray system theory. JOURNAL OF TRANSPORTATION ENGINEERING 130(1): 113-121.

17. Li Z, Hassan RA, Shahidehpour M, Bahramirad S, Khodaei A (2017) A Hierarchical Framework for Intelligent Traffic Management in Smart Cities. IEEE Transactions on Smart Grid p. 1.

18. Zhou M, Sisiopiku V (2008) Relationship Between Volume-to-Capacity Ratios and Accident Rates. TRANSPORTATION RESEARCH RECORD 1581: 47-52.

19. Asaithambi G, Mourie HS, Sivanandan R (2017) Passenger Car Unit Estimation at Signalized Intersection for Non-lane Based Mixed Traffic Using Microscopic Simulation Model. Periodica Polytechnica Transportation Engineering 45(1): 12-20.

20. Afshar, AAK, Tuydes-Yaman H (2014) Estimation of Level of Service at Signalized Intersections around the Proposed Health Campus in Etlik, Ankara Paper presented at the 11th International Congress on Advances in Civil Engineering.

21. Ghosh I, Chandra S, Boora A (2013) Operational Performance Measures for Two-Lane Roads: An Assessment of Methodological Alternatives. Procedia-Social and Behavioral Sciences 104(2): 440-448.

22. Nedevska I, Ognjenovic S, Murgul V (2017) Methodology for Analysing Capacity and Level of Service for Roundabouts with one Lane (HCM 2000) Procedia Engineering 187: 797-802.

23. Mahidadiya AN, Juremalani PJ (2016) Estimation of Passenger Car Unit value at Signalized Intersection. International Journal of Scientific Research in Science, Engineering and Technology 2(2): 1317-1324.

24. Jamil W-a j, Ibrahim WHW (2006) An Analysis of Unsignalized Intersection using aaSIDRA Software. UNIMAS-e Journal of Civil Engineering 4(2): 13-17.

25. Rao BS, Rambabu T, Rao DGV (2017b) Analysis Of Capacity and Level of Service At Uncontrolled Intersections Under Heterogeneous Traffic Condition 8(8): 181-190.

26. Mohan M, Chandra S (2016) Three methods of PCU estimation at unsignalized intersections. The InTernaTIonal Journal of TransporTaTIon research 10(2): 68-74.

27. Prothan JIJ, Islam M, Rahman A, Pramanik A (2017) Transportation System Analysis at the Major Road Intersection in the CBD Area of 
Rangpur City, Bangladesh. International Journal of Transportation Engineering and Technology 3(4): 74-82.

28. Chisty KU, Islam MA, Misuk S (2014) Determination of Level of Service of Agrabad to CEPZ Road at Chittagong in Bangladesh International Journal of Social, Behavioral, Educational, Economic, Business and Industrial Engineering 8(6).

29. Wikipedia (2018) Rajshahi.

30. Li J, Yue ZQ, Wong SC, M ASCE (2004) Performance Evaluation of Signalized Urban Intersections under Mixed Traffic Conditions by Gray System Theory. JOURNAL OF TRANSPORTATION ENGINEERING 130(1): 113-121.

31. Sahani R, Bhuyan PK (2013) Level of Service Criteria of off-street Pedestrian Facilities in Indian Context using Affinity Propagation Clustering. Transportation Research Group of India 104: 718-727.

32. Transportation DO (2013) Quality/ Level Of Service Handbook: Department Of Transportation.

33. CNG-ONE L (2018) The Benefits of Compressed Natural Gas (CNG) Vehicles.

34. Zheng Y, Zhang J, Zhang G, Li L, Ye B (2018) Survival Analysis on Passing Time of Minor Vehicle's Road Crossing at Un-Signalized Intersection in China. Green Intelligent Transportation Systems 419: 819-835.

35. Rao BS, Rambabu T, Rao DGV (2017a) Analysis Of Capacity And Level Of Service At Uncontrolled Intersections Heterogeneous Under Traffic
Conditions. International Journal of Civil Engineering and Technology 8(8): 181-190.

36. Sisiopiku VP, Byrd J, Chittoor A (2007) Application of Level-of-Service Methods for Evaluation of Operations at Pedestrian Facilities. Journal of the Transportation Research Board 2002: 117-124.

37. Department M E (2003) Traffic Engineering. Transportation.

38. Farooq D, Akram T (2018) Traffic Flow Analysis and Solutions to Ease Traffic Flow at Unsignalized Taxila Intersection. Periodica Polytechnica Transportation Engineering 46(2): 101-107.

39. Corespondent S (2017) 45 killed in four days NEW AGE.

40. Correspondent (2017) 3 killed in Rajshahi road crash. The daily Ovserber.

41. Desk SO (2017) Road crash injures 30 in Rajshahi. The daily sun.

42. Correspondent S (2017) Four killed in Rajshahi accidents The Daily Star.

43. Correspondent S (2017) Uncle-nephew killed in Rajshahi road accidents banglanews24.com.

44. Md Abdullah Al Imran, BAMK B (2014) Investigation of highway geometric problems and remedial measures in Rajshahi City corporation area, Bangladesh. International Journal of Advanced Structures and Geotechnical Engineering 3(2): 126-133.

45. Tarko AP, Perez-Cartagena RI (2005) Variability of Peak Hour Factor at Intersections. Transportation Research Record 1920: 125-130.

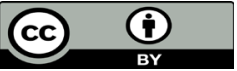

This work is licensed under Creative Commons Attribution 4.0 License

To Submit Your Article Click Here:

Submit Article

DOI: $10.32474 /$ TCEIA.2018.02.000145

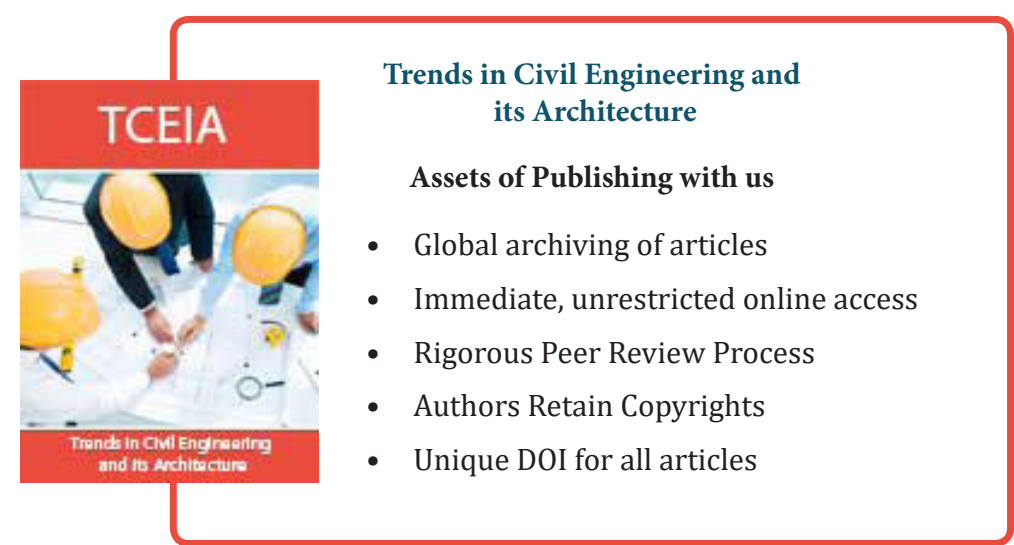

